\title{
The mechanosensitive Piezo1 orchestrating angiogenesis is essential in bone
}

\section{fracture repair}

Peng Chen ${ }^{1 \dagger}$, Gangyu Zhang ${ }^{3 \dagger}$, Shan Jiang ${ }^{3}$, Yile Ning ${ }^{2,3}$, Bo Deng ${ }^{2,3}$, Xianmei Pan ${ }^{2,3}$,

Silin $\mathrm{Liu}^{2,3}$, Yu He ${ }^{2,3}$, Lei Zhang ${ }^{2,3}$, Rentao Wan ${ }^{2,3}$, Zhiming Wu ${ }^{2,3}$, Qi He ${ }^{2,3}$, Jiang

Yin $^{5}$, Haibin Wang ${ }^{1}, \quad$ Jing $\operatorname{Li}^{1,2,4 *}$

${ }^{1}$ The First Affiliated Hospital, ${ }^{2}$ Lingnan Medical Research Center, ${ }^{3}$ The First School of Clinical Medicine, ${ }^{4}$ School of Pharmaceutical Sciences, Guangzhou University of Chinese Medicine, Guangzhou, 510405, China. ${ }^{5}$ The affiliated Cancer Hospital, Guangzhou Medical University, Guangzhou, China, 510095

$\dagger$ Equal contributors

*Author for correspondence:

Professor Jing Li, Lingnan Medical Research Center, Guangzhou University of Chinese Medicine, Guangzhou, 510405, China. Email: bmsjingl@gzucm.edu.cn

Short running title: Piezol channels in bone fracture repair

Key words: Piezol channels; endothelial knockout mice; angiogenesis; bone fracture; vascular biology

Conflict of interest: The authors have declared that no conflict of interest exists 


\begin{abstract}
Mechanical ion channel protein Piezol play vital roles in angiogenesis which has been proved to be high importance in varieties of biological processes. Bone formation in the fracture repair requires oxygen and nutrients from new blood vessels generated from fractured lesion. Understanding the underlying mechanisms linking angiogenesis and bone formation must be of great value for improved fracture healing. Here we employed mice with genetically modified endothelial specific depletion of Piezol channels to explore the hypothesis that Piezol is vital to the initiation of fracture healing. In this study, we demonstrated that Piezol expression and wide distribution along the bone and impaired endothelial Piezol channels result in derangements in bone fracture repair. Intriguingly, the calcium activated proteolytic caplain activity severely disrupted during vascularization, precluded osteoblast maturation and mineralization and subsequently the phosphorylated PI3K-AKT reduction. Furthermore, Piezol endothelial disruption impaired Notch signaling in bone union. These data collectively suggest that Piezol channels serve as a basis for clinical strategies to improve bone regeneration and treat delayed or nonunion in bone fracture.
\end{abstract}




\section{Introduction}

The skeleton is a complex multifunctional organ system and bone fractures are the traumatic injuries of the most common large-organs in humans. The bone repair following fractures is a postnatal regeneration in skeletal system and usually an efficient and rapid process involving both biological and mechanical aspects which aims at restoring the fractured bone to its biomechanical function and pre-damaged structure. Unfortunately, approximately 5\%-10\% injured bones manifesting delayed healing and/or nonunion results in restrained movements (1-3). The impaired fracture healing are often associated with a variety of risk factors including nutritional, biological as well as physical factors. Among these, neovascularization is believed to be crucial in normal bone healing(4-11). Several molecular players, for example, vascular endothelial growth factor (VEGF) signaling(12-14), hypoxia(15, 16), matrix metalloproteases (17-19), fibroblast growth factor (FGF) $(20,21)$ and Notch signaling $(22,23)$ had been intensively explored. However, the mechanism orchestrating angiogenesis during fracture healing has not been very well defined.

The recently discovered mechanically activated cationic ion channel Piezol, has proved as a $\mathrm{Ca}^{2+}$ permeable transmembrane protein activated by physical force $(24,25)$. It consists of a three blade assembled pore unit and formed a propeller like structure and is involved in multiple biological functions, which determined cells in responding to touch, cell volume, or stretching of the surrounding tissue through converting mechanical force into electrochemical signals (26-33). In previous studies, endogenous Piezol channels are highly expressed in vasculature where it directly sense the physiological shear stress imposed on endothelial cells (ECs) which have the key roles in vascular development $(34,35)$. Moreover, its function has been verified in physical exercise, vascular remodeling and lymphatic vascular development (36-41). More recently, Piezol channels, as the critical mechanotransducer in controlling mechanosensitivity in osteogenesis and mechanical force dependent bone formation has been confirmed $(42,43)$. 
Given the vital importance of Piezol in vascular endothelial cells, we speculate Piezol might play an essential role in bone formation and remodeling during bone fracture healing. We systematically detected the function of Piezol in this process using conditional Cre-Lox-mediated depletion of Piezol in the endothelium (Piezol ${ }^{\triangle E C}$ mice) and compared with their littermates (Piezol ${ }^{f l f l}$ mice). Our findings revealed that Piezol coupled to Notch signaling pathway to determine bone remodeling.

\section{Results}

\section{Vascular expression and distribution of Piezol in bone tissue}

It has been reported that Piezol ion channels are widely expressed in a variety of cells and organs. To examine the vascular arrangement of Piezol channels in bone, we employed knock-in reporter mice wherein a tandem-dimer Tomato (tdT) fluorescent protein is tagged to the C-terminus of the Piezol channels, which has been confirmed that the expression levels and patterns are of the same as the endogenous Piezol channels $(35,44)$. Immunostaining showed bone vasculature labeled with endomucin $(E M C N)$ that is a membrane-bound glycoprotein expressed on the surface of endothelial cells and the Piezol-tdT labelling with an anti-RFP antibody as indicated by the representative confocal images (Fig. 1A). Piezol-tdT was found localized in a large proportion to endomucin-labeled endothelial cells. In line with this result, western blot analysis revealed that the Piezol-tdT fusion protein was readily detected in bone tissue from Piezol-tdT mice and no signal was observed in lysates obtained from Piezol wildtype $\left(\right.$ Piezol $\left.^{+/+}\right)$mice (Fig. 1B). The data suggest that endothelial Piezol is abundant in bone vasculature.

\section{Piezo1 $^{\triangle E C}$ mice generation and validation}

To detect the endothelial Piezol specific disruption in mice we freshly isolated liver endothelial cells from Piezol ${ }^{\triangle E C}$ and Piezol ${ }^{f l f l}$ mice. Gel electrophoresis of PCR endpoint products, quantitative RT-PCR analysis and Yoda1 induced calcium entry in liver endothelial cells from Piezol ${ }^{\triangle} E C$ and Piezol ${ }^{f l f l}$ mice revealed the specific knockout of Piezol in endothelium (Fig. 2A-D). In contrast, ATP induced calcium entry showed no 
difference in liver endothelial cells from Piezol ${ }^{\triangle E C}$ and Piezol ${ }^{f l f l}$ mice (Fig. 2E). Thus, we next focus on investigating the function of endothelial Piezol in skeletal system.

\section{Piezo1 $^{A E C}$ mice show severely impaired bone formation}

To determine the potential role of Piezol during bone fracture repair, we performed stabilized femur fractures on Piezol ${ }^{\Delta \mathrm{EC}}$ and their littermates (Piezol ${ }^{\text {flffl }}$ ) when mice were injected with tamoxifen one week later. As shown in macro-images (Fig. 3A), callus has been well-formed and remodeling at the fracture ends at 21 days post fracture (DPF) and 42 DPF in Piezol ${ }^{f l f l}$ mice. In contrast, callus was still defective at the fracture site by $21 \mathrm{DPF}$ and callus resorption has not finished even by 42 DPF. Similarly, X-ray and 3D $\mu \mathrm{CT}$ in Piezol ${ }^{f l f f l}$ fractures illustrated external callus formed completely at the fracture site by $21 \mathrm{DPF}$, followed by the completion of bone remodeling by $42 \mathrm{DPF}$, suggesting bone fracture well unified. Even though Piezol ${ }^{\triangle E C}$ mice demonstrated remarkable callus formation along the periosteum extending away from the fracture line, no bridging callus was clearly observed by 21 DPF. And even more, radiographic evident up to 42 DPF still highlighted a clear radiolucent gap between broken ends (Fig. 3B and 3C). Further analysis of the periosteal callus around the site of fracture revealed more bony trabecular and foci of mineralization in axial $\mu \mathrm{CT}$ at 21 and $42 \mathrm{DPF}$ in Piezol ${ }^{\text {flfl }}$ mice than i Piezol ${ }^{\triangle E C}$ mice (Fig. 3D). Consistently, coronal view from 3D

$\mu \mathrm{CT}$ data of Piezol ${ }^{f l f l l}$ fractures showed a nearly complete bridging of bony calluses by 21 DPF, followed by complete bridging by 42 DPF. Piezol ${ }^{\triangle E C}$ fractures presented with a large gap between fracture cortices sties up to and beyond 42 DPF (Fig. 3E). Quantitatively, at 21 and $42 \mathrm{DPF}$ in Piezol ${ }^{\triangle E C}$ mice, trabecular bone volume fraction (BV/TV), trabecular thickness (Tb.Th), trabecular number (Tb.N) were significantly decreased while trabecular separation (Tb.Sp) increased compared to their littermates which indicated the fracture union delayed or fracture nonunion. The data suggest the obvious nonunion developed in bone fracture in Piezol endothelial depletion mice.

\section{Piezo1 ${ }^{\triangle E C}$ mice show less expression of endomucin (EMCN), RUNX2 and Osterix} (Osx) during bone formation

Given that endothelial Piezol channels are crucial in vascular formation in development, we hypothesized that depletion of Piezol in endothelial cells might affect angiogenesis 
and subsequent osteogenesis in bone repair. We performed immunostaining on regional sections of fractured femurs. As demonstrated in Fig. 4A and B, EMCN, a sialoprotein expressed by non-arterial endothelial cells, was less abundant around fracture site in Piezol ${ }^{\triangle E C}$ mice than that in Piezol ${ }^{f l f l}$ mice, indicating impaired new blood vessels formation. To further determine whether osteogenesis factors, $R U N X 2$, which has a crucial role in the early determination stage of the osteoblast lineage and Osterix (Osx), which regulates the late stage of osteoblast differentiation and bone formation were affected by endothelial Piezol knockout mice, we found both RUNX2 and OSX were dramatically decreased in Piezol ${ }^{\triangle E C}$ mice compared with Piezol ${ }^{f l f l}$ mice, as shown in Fig. 4C and Fig. 4E and quantified the fluorescent intensity in Fig. 4D and Fig. 4F. The data suggest that endothelial Piezol has key roles in soft and hard callus formation through angiogenesis which providing the blood and nutrients in bone fracture healing process.

\section{Loss of endothelial Piezo1 impairs bone fracture healing by histological examination}

To better examine the role of Piezol during bone fracture repair, histological staining was employed to determine the calluses formed between the fracture gap and periosteum. At $21 \mathrm{DPF}, \mathrm{H} \& \mathrm{E}$ staining exhibited complete continuity of the cortex with mature lamellar structure in Piezol ${ }^{f l f l}$ mice (Fig. 5A upper). Meanwhile, ABH/OG and SFO/FG staining revealed that the morphology and the sizes of cartilage-like or bonylike calluses formed between the fracture gap and periosteum. Activated osteocytes (bright blue with pericellular rings in Fig. 5B upper) and cartilage-containing areas (red area in Fig. 5C upper) also reflected the strong osteoblastic activity, whereas no healing evident in Piezol ${ }^{\triangle E C}$ mice. In place of normal healing, Piezol ${ }^{\triangle E C}$ mice osteotomies remained a clear broken gap at broken sites and no obvious osteocytes and ossification centers. At $42 \mathrm{DPF}$, bony calluses were reduced to normal cortical bone by bone remodeling process in Piezol ${ }^{f l f l}$ mice. However, fracture line was still evident even the occurrence of adipose vesicles in Piezol ${ }^{\triangle E C}$ mice. (Fig. 5A-C lower parts).

\section{Loss of Piezo1 severely impairs angiogenesis}

Blood supply to the fracture sites is essential for bone fracture repair. In order to 
determine the role of Piezol on angiogenesis in the process of bone fracture healing, we employed Microfil perfusion and found that visible new blood vessels were formed around the fracture site in Piezol ${ }^{f l f l}$ mice at $21 \mathrm{DPF}$ compared with Piezol ${ }^{\triangle E C}$ mice. Furthermore, the blood vessel turned out to be close to normal in Piezol ${ }^{f l f l}$ mice at 42 DPF while the blood vessel in Piezol ${ }^{\triangle E C}$ mice remained interrupted (Fig. 6A). Quantitatively, not only the vessel volume (fraction), but also the vessel surface were significantly lower in Piezol ${ }^{\triangle E C}$ mice than in their littermates both by 21 and 42 DPF (Fig. 6B). In accordance with our expectations, these data reveal that Piezol is able to orchestrate angiogenesis during fracture healing.

\section{Loss of Piezo1 remarkably reduces biomechanical properties}

We next sought to determine whether the altered fracture repair processes have the impact on bone structure. To this end, we analyzed the mechanical properties of fracture femora by three-bending test. As expected, we found yield load and bending stiffness were significantly decreased in samples of $21 \mathrm{DPF}$ in Piezol ${ }^{\triangle E C}$ mice compared to Piezol ${ }^{f l f l}$ mice. Although the two parameters were slightly enhanced by 42 DPF in Piezol ${ }^{4 E C}$ mice compared to $21 \mathrm{DPF}$, there were still remarkably lower than Piezol ${ }^{\text {flffl }}$ mice (Fig. 7). These data indicate that biomechanical properties are indeed reduced with the loss of endothelial Piezol.

\section{Piezo1 endothelial depletion impairs calpain activity}

To gain insight into the mechanistic understanding of the role of Piezol channels in fracture healing, we next performed the calpain activity assay, given that Piezol channels can activate calpain, a cytoplasmic cysteine protease which requires calcium ions for its function and subsequently mediates a variety of intracellular processes including cleaving focal adhesion proteins and cytoskeletal substrates to impair angiogenesis (34). We found that there was significantly decreased calpain activity in Piezol ${ }^{\Delta E C}$ mice compared to Piezol flfl mice, suggesting that Piezol activation of calpain was responsible for bone reunion (Fig. 8A).

\section{Piezo1 endothelial depletion couples to PI3k-AKT pathway and Notch signaling in fracture repair}

Piezol serves as a non-selective cationic ion channel that allows $\mathrm{Ca}^{2+}$ entry and initiates 
a $\mathrm{Ca}^{2+}$ dependent downstream signals. Previous studies have demonstrated that $\mathrm{Ca}^{2+}$ entry mechanism could lead to phosphorylation of PI3K-AKT and thus regulate proliferation, migration and angiogenesis in endothelial cells $(45,46)$ and promote osteoblast differentiation and mineralization(47). A mechanical stimulation mediated Piezol-Akt pathway in osteocytes is required for bone homeostasis (48) In line with these reports, we identified that the phosphorylation of $P I 3 K$ and $A K T$ was dramatically decreased in Piezol ${ }^{\triangle E C}$ mice compared to Piezol ${ }^{f l f l}$ mice at the fracture lesions. Furthermore, CD31( PCAM-1), and Notch1 intracellular domain (N1ICD), the key players in promoting flow induced angiogenesis, were downregulated in Piezol ${ }^{\triangle E C}$ mice compared to Piezol flffl mice (Fig. 8B) and quantified in (Fig. 8C). Consistently, the expression levels of Hesl and Heyl, the Notchl regulated genes, showed dramatic reduction in Piezol ${ }^{\triangle E C}$ mice compared with in Piezol ${ }^{f l f l}$ mice (Fig. 8D). Taken together, the data suggest that endothelial deficiency of mechanosensitive Piezol channels significantly impairs the $\mathrm{Ca}^{2+}$ dependent bone angiogenesis and ossification in bone fractural healing processes.

\section{Discussion}

To investigate whether Piezol ion channels, which contribute crucially to vascularization in early development in mice, are playing roles in bone fracture healing process we examined mice with stabilized fracture in endothelial specific deletion of Piezol channels. These studies revealed that the exact Piezol expression architecture of the bone vasculature and demonstrated strikingly that Piezol is an important player in vascularization in bone fracture reunion and that the impaired $\mathrm{Ca}^{2+}$ entry mediated proteolysis calpain activation upon Piezol endothelial depletion. Furthermore, we found that a positive feedback relationship between Piezol channel and PI3K-AKT downstream pathway as well as CD31 and Notch signaling in regulating bone new vessel formation and bone ossification.

It has been widely reported that bone fracture healing contains a more complex process and is different from a wound repair which creates a fibrous scar in a soft tissue. The 
steps of fracture repair include hematoma formation where broken of blood vessels result in inflammatory cells release and coagulation cascade activation and soft and hard callus formation where intramembranous ossification, the internal callus becomes mineralized when angiogenesis occurred and finally the fractured bone remodeling by returning vascular structure and replace the damaged bone(49). In the past years, extensive studies have led to the discovery of a large number of growth factors that stimulate angiogenesis, which are very important in bone development and normal fracture healing. Notch signaling is one of the most well investigated angiogenic factors in the mammalian skeletal system and has been proved that manipulation of Notch receptors lead to desired successful fracture repair in femoral fracture and cortical bone defects in mice. Consistently our experiments showed that depletion of Piezol reduced Notchl expression and further proved Notch signaling pathways are indispensable for vascularization, callus formation and mineralization while the bone was injured. These findings provide also the notion that Piezol combined with Notch is the key mechanism where angiogenesis and osteogenesis are tightly coupled in bone repair.

There are increasing recognition of calpain mediated signaling pathway in angiogenesis. Several seminal studies have revealed that VEGF induced calpain dependent activation of PISK-AKT cascade, subsequent release of nitric oxide and generation of physiological angiogenesis. We have reported that when HUVECs overexpressing Piezol-WT-GFP plasmid-were applied with flow accumulation of Piezol-WT-GFP at the leading apical lamellipodia were achieved which facilitating HUVECs to migrate and thus form the new blood vessels. The harmonization of cytoskeleton and focal adhesion was controlled importantly by calpain. We further reported that at embryonic E9.5 and 10.5 stages global disruption of Piezol led to the decreased calpain activity. In line with this findings it is a new paradigm that the important roles of Piezol in angiogenesis and bone repair and remodeling during fracture.

In present studies we focused only on the endothelial function of Piezol in bone fracture healing, As mentioned previously, the critical roles of Piezol channels in bone 
development have been published by two groups $(42,43)$ and based on the widely expression of Piezol in red blood cells, macrophages, monocyte and leucocytes, we postulated that the role of Piezol channels in impaired fracture repair may be functionally involved a more complex picture. Although there are many unanswered questions we are still facing the great opportunity to explore the precise role of bone EC subsets and blood vessels in physiological and pathophysiological environments, which will improve our mechanistic understanding of the skeletal system from the cellular and molecular aspects. Further extensive studies are needed to investigate the crosstalk between different signaling regulations and to elucidate the potential therapeutic applications aimed at preventing bone loss or stimulating fracture healing.

In summary, our results indicate that Piezol channels play an important role in regulating $\mathrm{Ca}^{2+}$ entry mechanism and local vascular growth and provide valuable niche signals for osteogenesis and in reducing Notchl expression in fracture healing. Although mouse models of fracture healing very closely reproduce the process found in humans, they may not be exactly the same. As yet pharmacologically intervention of Piezol channels has limited but with high resolution cryo-EM structure identification of Piezol channels there will be more effective small molecules to be synthesized and clinically applied to the patients. Nevertheless, our data provide insight into how mechanical sensitive endothelial cells can promote bone fracture healing processes, particularly in regard to vascularization through a Piezol regulated mechanism.

\section{Materials and Methods}

\section{Genetically modified mice}

All animal studies were carried out with approval from Animal Care and Use Committee of Guangzhou University of Chinese Medicine. The Cre/loxP system was introduced to obtain the conditional knockout mice. Endothelial-cell-specific gene deletions mice were created and characterized by intercrossing Cdh5 (PAC)-CreERT2 transgenic mice (a gift from Ralf Adams, University of Münster, Münster, Germany) with conditional mutants containing loxP flanked Piezol (Piezol ${ }^{\text {lox/lox }}$ ). In order to 
achieve Cre activity and gene deletion, offspring mice of 8-week old were treated with $500 \mathrm{mg}$ tamoxifen (Sigma, T5648) intraperitoneally (i.p.) for 5 consecutive days. Although experimenters were not blinded when dividing mice into experimental groups, we definitely conduct fracture performance and end-point harvesting under blindness. Mice with the fused sequence for tdTomato (Piezol-tdT) at the C-terminus of Piezol and Piezol ${ }^{l o x / l o x}$ were purchased from The Jackson Laboratory. PCR test were used to genotype all mice. Protocols for PCR experiment and sequences for primers will be available upon request.

\section{Establishment of open femoral shaft transverse fracture mice model}

A unilateral (right side) open transverse femur fracture was performed according to previously described protocols with modifications (50). Briefly, mice were anesthetized with $1 \%$ pentobarbital $(50 \mathrm{mg} / \mathrm{kg})$ by intraperitoneal injection. We depilated the right leg with an electric shaver and cleaning the local area with an alcohol wipe, prior to making an incision above the right anterolateral femur. Muscle were separated by blunt dissection and exposed the middle shaft femur. When patella was flipped outwardly, a 27 gauge syringe needle was inserted into the medullary cavity paralleling with the long axis of the femur through the center of trochlear groove. The needle was then pulled out, and transverse diaphyseal fracture was created in the middle of the femur with fine scissors. Then, a 26 gauge syringe needle was aseptically introduced into the bone marrow cavity through the fracture line to achieve the fracture stabilization. The tail of needle was trimmed carefully to protect patellofemoral joint movement. The periosteum remained intact and soft tissues were well protected. Before closing the wound, neither partial fracture nor comminuted fracture was confirmed. A 4-0 silk suture was used to stitch the wound. After recovery from anesthesia, mice were placed back to their home cages with free movement. In the first three days after operation, penicillin ointment was used to avoid wound infection while buprenorphine was administered in drinking water for pain relief. Fracture repair was followed radiographically using a micro CT (Skyscan 1176 model, Bruker) weekly under anesthesia.

\section{High-resolution 3D confocal imaging acquisition and quantitative analysis}


The injured femora were dissected at 21 or 42 days after operation. During the procedure, all the surrounding muscles attached to the femur were carefully excoriated to avoid causing any mechanical damage to bones and callus tissue. The intramedullary needles were also removed carefully. We then strictly followed the standard protocol for immunofluorescence (51). Fresh bone samples were immediately fixed in ice-cold $4 \%(\mathrm{wt} / \mathrm{vol})$ paraformaldehyde (PFA) solution for $4 \mathrm{~h}$ in a $15 \mathrm{~mL}$ conical tube sitting on the ice. We washed the bone tissues in 3 changes of sterile 1X PBS (7 mL) for $5 \mathrm{~min}$ at $4{ }^{\circ} \mathrm{C}$ each time with persistent agitation to make sure that all of the PFA was completely removed. Then, we added ice-cold 0.5 M EDTA (10 mL, PH 7.4) and incubated the mixture at $4{ }^{\circ} \mathrm{C}$ under constant shaking up to $24 \mathrm{~h}$ (this decalcification step could be assessed by pressing the sample with a forceps), followed by bone samples being washed 3 times with $7 \mathrm{~mL}$ of PBS and each time for $5 \mathrm{~min}$ at $4{ }^{\circ} \mathrm{C}$ under constant agitation. PBS was removed completely from the tube and $10 \mathrm{~mL}$ of ice-cold cryoprotectant (CPT) solution was added for $24 \mathrm{~h}$. After completely remove CPT, bone samples were transferred to a tissue mold and immediately embedded with freshly made embedding solution (EBM) of approximately $5 \mathrm{~mL}$ without any bubbles or solid particles (the tissue mold must be filled up completely with EBM). The samples were incubated for half an hour at RT to ensure EBM totally solidification followed by 45 min of incubation at $60^{\circ} \mathrm{C}$ in water bath. Subsequently, we transferred the samples to $80^{\circ} \mathrm{C}$ for storage overnight, before placed the samples for section with a thickness of $50 \mu \mathrm{m}$ (the cryotome was set at low speed of 20-40\%).

For immunofluorescence staining, we rehydrated the sections by incubating bone slides with $200 \mu \mathrm{L}$ of PBS for $5 \mathrm{~min}$ at RT and then $200 \mu \mathrm{L} 0.3 \%$ (vol/vol) Triton X-100 permeabilization (PRM) solution at RT for $20 \mathrm{~min}$. Then, we used donkey serum (5\%) to block sections for half an hour at RT and incubated them overnight at $4{ }^{\circ} \mathrm{C}$ with 200 $\mu \mathrm{L}$ of primary antibody solutions: RFP (600-401-379, 1:100; Rockland), Endomucin (EMCN, sc-65495, 1:100; Santa Cruz), RUNX2 (ab23981, 1:100; Abcam), Osterix (OSX, ab22552, 1:100; Abcam). After primary antibody incubation, slides were rinsed 3 changes with PBS for 5 min each and incubated with $200 \mu \mathrm{L}$ of fluorescentconjugated secondary antibody at RT for 60 min while light avoidance. After that, 
sections were washed with 3 changes of $1 \mathrm{X}$ PBS for 5 min each. Then, the nuclei were counterstained with freshly prepared 4', 6-diamidino-2-phenylindole (DAPI). We preformed all immunofluorescence experiments at least three times. We used Leica TCS SPEII confocal microscope for imaging samples with tile z-stack sequential scanning. We quantified all high resolution confocal images with ImageJ software.

\section{High-resolution in-vivo $\mu \mathrm{CT}$ of Piezol ${ }^{f l f l}$ and Piezo1 ${ }^{4 E C}$ mice}

The operated femora were imaged weekly from the first day after surgery to 42 days under anesthesia with high-resolution in-vivo $\mu$ CT scanner (Skyscan 1176, Bruker, MA, USA). The scanner was set up with an AI $(0.5 \mathrm{~mm})$ filter. The tube voltage was set to $50 \mathrm{kV}$ with the beam current $500 \mu \mathrm{A}$. The scanning angular rotation was set as $180^{\circ}$ while the angular increment was $0.50^{\circ}$ with isotropic voxel size of $9.02 \mu \mathrm{m}$. We employed image reconstruction software (NRecon V1.6.9), data analysis software (CTAn v1.9) and three-dimensional model visualization software ( $\mu$ CTVol v2.0) for analyzing the parameters of the fracture site. Two-dimensional morphometric analysis of the cortical bone and three-dimensional histomorphometric evaluation of the trabecular bone were performed with established cross-sectional images of the femora. Trabecular bone region of interest (ROI) was drawn commencing at the upper 500 slices to the lower 500 slices at the center of fracture line. Respectively, we segmented the images into trabecular bone and bone marrow. The parameters of trabecular bone volume fraction (BV/TV), trabecular thickness (Tb.Th), trabecular number (Tb.N) and trabecular separation (Tb.Sp) were further analyzed.

\section{Histological analysis}

Femora samples were harvested from Piezol mice at 21 DPF and 42 DPF, respectively. Under the condition of euthanasia, fracture femora were dissected and then fixed in $4 \%$ PFA. We decalcified the tissues with 0.5M EDTA ( $\mathrm{pH}$ 7.4) for 2 weeks and dehydrated them in an ascending ethanol series, then in xylene for clear. Tissues were processed to be embedded in paraffin and $6 \mu \mathrm{m}$ longitudinally thickness sections were cut by microtomes. All fixation and decalcification steps were carried out at RT.

For Hematoxylin \& Eosin (H\&E) stain, slides were deparaffinized and rehydrated by distilled water. Then, we placed slides into Hematoxylin solution for 5-10 min and 
washed them in tap water for 1 to 5 min until sections became blue. Sequentially, slides were soaked in Eosin solution for about 30 seconds and then rinsed in tap water when water became clear again. Then, slides were dehydrated by 2 times of $95 \%$ ethanol, cleared in 2 times of xylene for 5 min before mounting on coverslips using 3-4 drops of Permount.

For Alcian Blue Hematoxylin/ Orange G (ABH/OG) stain, slides were deparaffinized and rehydrated by distilled water. Then, slides were immersed into acid-alcohol for 30 seconds and drain briefly and stained with Alcian Blue Hematoxylin working solution for $40 \mathrm{~min}$. Sections were next rinsed gently with tap water until excess stain stops leaching from tissue. Then, slides were differentiated in acid-alcohol for 3 second and washed by distilled water 2 times. Sequentially, slides were dipped into $95 \%$ ethanol for 1 minute and placed in Eosin solution for 90 seconds. Then, slides were mounted on coverslips with Permount following by dehydrated by 3 changes of $95 \%$ ethanol and 2 changes of $100 \%$ ethanol and cleared in 3 changes of xylene.

For Safranin Orange/Fast Green (SFO/FG) stain, slides were baked at $60^{\circ} \mathrm{C}$ overnight and cooled down at RT about 20-30 min. Then, we deparaffinized the slides and hydrated them with $70 \%$ ethanol. Following that, we stained the slides by immersion in freshly prepared working Weigert's hematoxylin for $7 \mathrm{~min}$ and quickly rinsed them with running tap water until it runs clear (approximately $10 \mathrm{~min}$ ). Then, slides were immersed in working $0.08 \%$ fast green solution for $3 \mathrm{~min}$ and washed immediately by $1 \%$ acetic acid for 10 seconds. Slides were then stained with $0.1 \%$ safranin O solution for 5 min. Ultimately, slides were dehydrated by passage through 2 times of $95 \%$ ethanol and $100 \%$ ethanol for 3 min each and then cleared in 2 times of xylene for 5 min. Slides were then coverslipped by Permount.

\section{CT based microangiography}

In order to characterize the blood vessels during bone fracture healing process at 21 DPF and 42 DPF respectively, CT based angiography of microfil perfusion was introduced in this study. Briefly, experimental animals were anesthetized with $1 \%$ pentobarbital $(50 \mathrm{mg} / \mathrm{kg})$ by intraperitoneal injection and positioned supine. After exposing thoracic cavity, we irrigated the vascular system through $0.9 \%$ saline solution 
containing heparin sodium $(100 \mathrm{U} / \mathrm{mL})$ by inserting a blunt 22 gauge needle into the left ventricle. Immediately, we cut the right atrium open to ensure systemic blood outflows and continued flushing when the blood was thoroughly expelled from circulation. Microfil MV-122 (Flow Tech, USA), a low-viscosity radiopaque polymer, was used to identify the circulatory system followed by the specimens were fixed with $10 \%$ neutral buffered formalin under constant pressure. In order to confirm entirely filled with the vasculature, we assessed the extravascular pooling by judging the appearance of both the liver and the last organ to be perfused prior to extravasation through the right atrium. Mice were included in our study only with the complete hepatic blanching prior to Microfil obtained, or the contrast was very clear, or without extravascular pooling occurrence. Mice were kept at $4{ }^{\circ} \mathrm{C}$ and maintained overnights to enable contrast agent polymerization. Femora were then dissected and immersed in $10 \%$ neutral buffered formalin for 4 days for totally fixation. Following that, all fracture samples were decalcified for $48 \mathrm{~h}$ in a $0.5 \mathrm{M}$ EDTA (PH 7.4) and then acquired images again by $\mu \mathrm{CT}$ imaging system (Skyscan 1172). CTAn was used to reconstruct and quantify the vascular model.

\section{Biomechanical testing}

3-point bending test was introduced to determine the bone mechanical properties with Electroforce 3220 (Bose Corporation, USA). Experiment was conducted with the load point in displacement control, moving at a speed of $0.03 \mathrm{~mm}$ per second. Each sample was put in the same orientation with the cranial surface sitting on the supporting surface. Yield load $(\mathrm{N})$ and bending stiffness $\left(\mathrm{N}-\mathrm{mm}^{2}\right)$ were analyzed in accordance with the force and displacement data acquired in the tests.

\section{Calpain activity assay}

Calpain activity assay kit (Abcam, ab65308) was used to measure calpain activity with detection of cleavage of calpain substrate. Briefly, mice bone samples were dissected, homogenized and re-suspended in the provided extraction buffer. Protein concentration was determined and the inputs were standardized according to total protein content. Subsequently $100 \mu \mathrm{g}$ of lysate was transferred to the wells in a black 96 well plate format. The plate was incubated for $1 \mathrm{~h}$ at $37^{\circ} \mathrm{C}$ in the dark with reaction buffer and 
substrate. After which the fluorescence reading was made with a plate reader equipped with excitation at $400 \mathrm{~nm}$ and emission at $505 \mathrm{~nm}$. Absorbance Signals in arbitrary units were presented after subtraction of background and were shown as the relative calpain activity.

\section{Western blot analysis}

Western blot analysis was carried out according to a previously described standard protocol (52). Proteins from fracture femora were extracted by RIPA buffer combined with protease inhibitors and phosphatase inhibitors (Roche). The supernatants were obtained by centrifugation $\left(12,000 \mathrm{~g}, 10 \mathrm{~min}, 4{ }^{\circ} \mathrm{C}\right)$. Protein concentration was determined utilizing the Pierce BCA Protein Assay kit. Equivalent amounts of protein in the specimen were separated based on their molecular weight by electrophoresis on 8\% Bis-Tris gels and transferred to polyvinylidene difluoride (PVDF) membranes (Life Technologies). Membranes were immediately blocked with 5\% nonfat dried milk diluted in TBST and incubated with primary antibodies (1:1,000, RFP from Rockland; p-PI3K, Cat: 17366s; PI3K, Cat: 4257s; Akt, Cat: 9272s; p-Akt Ser473, Cat: 9271s and Notch1, Cat: 4147 Val1744 D3B8, Rabbit mAb from Cell Signaling Technology; CD31, Cat: ab28364 from abcam) overnight at $4{ }^{\circ} \mathrm{C}$. After 3 times rinses with TBST, membranes were incubated with horseradish peroxidase (HRP)-linked secondary antibodies. The protein bands were detected by ECL reagents (GE Healthcare) and the ChemiDoc XRS+ System (Bio-Rad). Duplicate experiments and analyses were performed at least 3 times.

\section{RT-PCR}

Total RNA was extracted using a Tri-reagent protocol from femurs flushed to remove bone marrow followed by DNase I (Ambion) treatment. Reverse transcription (RT) was performed using a high capacity RNA-to-cDNA kit (Thermo Fisher, USA). The specificity of PCR was verified by performing reactions without RT and melt-curve analysis. Sequences of PCR primers were: Mouse Piezol (forward), 5'GCTTGCTAGAACTTCACG-3', (reverse) 5'-GTACTCATGCGGGTTG-3'; Mouse Hesl (forward), 5'-CCTCTGAGCACAGAAAGTCA-3', (reverse) 5'GCCGGGAGCTATCTTTCTTA-3'; Mouse Heyl (forward), 5'- 
GTACCCAGTGCCTTTGAGAA-3', (reverse) 5'-TTTCAGGTGATCCACAGTCA-3'. PCR products were electrophoresed on $1.5 \%$ agarose gels and sequenced to recognize their identity. PCR was performed on a CFX96 Real-Time PCR detection system (Biorad) using SYBR Green Premix Ex Taq II (Takara, Dalian, Liaoning, China). All the 2$\Delta \Delta \mathrm{CT}$ values were normalized using the reference gene $\beta$-actin.

\section{Isolation of liver endothelial cells}

Murine liver tissues were kept in cold EBM-2 medium. Endothelial cells were isolated using CD31-conjugated microbeads (Miltenyi Biotec). Initially, the tissue was minced and resuspended in a disgestive solution consisting of $9 \mathrm{~mL} 0.1 \%$ collagenase II, $1 \mathrm{~mL}$ $2.5 \mathrm{U} \cdot \mathrm{mL}^{-1}$ dispase, $1 \mu \mathrm{M}$ magnesium chloride and $1 \mu \mathrm{M}$ calcium chloride in Hanks Buffer. The tissue-dissociation mix was incubated in a MACSMix Tube Rotator (Miltenyi Biotech) for 45 min at $37^{\circ} \mathrm{C}$ with continuous stirring. At the end of enzymatic dissociation, the sample was passed through $100 \mu \mathrm{m}$ and $40 \mu \mathrm{m}$ cell filters to remove undigested tissue, Cells were washed twice in magnetically activated cell sorting (MACS) buffer composed of PBS with $0.1 \%$ bovine serum albumin (BSA) and $2 \mathrm{mM}$ EDTA at pH 7.2 followed by suspended in $20 \mathrm{~mL}$ red blood cell lysis buffer containing $0.206 \mathrm{~g}$ Tris base and $0.749 \mathrm{~g} \mathrm{NH}_{4} \mathrm{Cl}$ in $100 \mathrm{~mL} \mathrm{PBS}(\mathrm{pH}$ 7.2) for $10 \mathrm{~min}$, and then washed for a final time in MACS buffer. Next the pellet was incubated with $200 \mu \mathrm{L} / 1$ $\times 10^{7}$ total cells of dead cell removal paramagnetic microbeads (Miltenyi Biotec) and incubated for 15 min at RT. After incubation, the cells were passed through a LS column prepared with $1 \times$ Binding Buffer (Miltenyi Biotec) in a magnetic field (MiniMACS Separator, Miltenyi Biotec). The elute was incubated with $30 \mu \mathrm{L} \mathrm{FcR} \mathrm{blocking} \mathrm{reagent}$ and $30 \mu \mathrm{L}$ CD31-conjugated paramagnetic microbeads (Miltenyi Biotec) for $15 \mathrm{~min}$ at $4^{\circ} \mathrm{C}$. After incubation, the solution was prepared with an MS column and MACS buffer. CD31-positive cells remained in the column, and CD31 negative cells passed through as eluents. CD31-positive cells were washed with warm EBM-2 medium, placed in one well of a fibronectin coated 6-well plate, and incubated in a 5\% CO2 incubator. Medium was changed at $12 \mathrm{~h}$, and then every $48 \mathrm{~h}$ until ready to be used.

\section{Intracellular calcium measurements}


Liver endothelial cells were incubated for $1 \mathrm{~h}$ at $37^{\circ} \mathrm{C}$ with $1 \mu \mathrm{M}$ Fura-2 AM (Thermo Fisher Scientific, USA) and 0.1\% pluronic acid in Standard Bath Solution (SBS): 130 $\mathrm{mM} \mathrm{NaCl}, 8 \mathrm{mM}$ D-glucose, $5 \mathrm{mM} \mathrm{KCl}, 10 \mathrm{mM}$ HEPES, $1.5 \mathrm{mM} \mathrm{CaCl}_{2}$ and $1.2 \mathrm{mM}$ $\mathrm{MgCl}_{2}$, titrated to $\mathrm{pH} 7.4$ with $\mathrm{NaOH}$. Cells were washed three times in SBS. Measurements were made at RT $\left(21 \pm 2^{\circ} \mathrm{C}\right)$ and excited with 340 and $380 \mathrm{~nm}$ light, and emissions was collected at $510 \mathrm{~nm}$. The change of intracellular $\mathrm{Ca}^{2+}$ concentration was expressed by the change of Fura-2 fluorescence ratio at two excitation wavelengths.

\section{Statistical analyses}

All data were presented as the mean \pm SEM, where $n$ indicates the number of independent experiments. Unpaired, two-tailed Student's t-tests were used in this study for comparing two groups. For some data sets, one-way ANOVA followed by Tukey's multiple comparison test was used. No animals or samples were eliminated from analysis, and when applicable, animals were randomly assigned to treatment and control groups. In our experiments, $P<0.05$ were regarded to be significant and indicated by '*'. The Origin software (8.5) was used for statistical analysis.

\section{Materials}

Unless stated separately, all chemicals that used were purchased from Sigma-Aldrich. Fura-2-AM (molecular probe) was dissolved in DMSO at a concentration of $1 \mathrm{mM}$. Pluronic acid F127 was in DMSO of $10 \% \mathrm{w}^{-1} \mathrm{v}^{-1}$ and stored at RT. Yoda1 (Tocris) was prepared as a $10 \mathrm{mM}$ stock solution.

\section{Acknowledgments}

The study was supported by the National Natural Science Foundation of China (NSFC 81770453, 81774339, 81603641).

\section{Author contributions}

PC, GZ, SJ ZW, QH conducted and analyzed the experiments. YN, BD, XP, SL, YH, RW and LZ helped in generation and management of mice breeding. GZ, LZ and SL performed the immunostaining experiments. GZ, SL, JY and LZ performed data analysis. HW provided intellectual input. JL conceived the idea for the project, generated research funds, led and coordinated the study. JL designed the study and 
wrote the paper with the help from PC. All authors reviewed the results, commented on the manuscript, and approved the final version of the manuscript. 


\section{References}

1. Einhorn TA. Enhancement of fracture-healing. 1995;77(6):940-56.

2. Ebraheim NA, Martin A, Sochacki KR, and Liu J. Nonunion of Distal Femoral Fractures: a Systematic Review. Orthop Surg.5(1):46-50.

3. Robinson CM, Court-Brown CM, Mcqueen MM, and Wakefield AE. Estimating the Risk of Nonunion Following Nonoperative Treatment of a Clavicular Fracture. JBJS. 2004;86(7):676-7.

4. Cobb TK, Gabrielsen TA, Campbell DC, Wallrichs SL, and Ilstrup DM. Cigarette Smoking and Nonunion after Ankle Arthrodesis. Foot \& Ankle International.15(2):64-8.

5. Macey LR, Kana SM, Jingushi S, Terek RM, and Bolander ME. Defects of early fracture-healing in experimental diabetes. Journal of Bone \& Joint Surgery American Volume. 1989;71(5):72233.

6. Gruber R, Koch Hr, Doll BA, Tegtmeier F, Einhorn TA, and Hollinger JO. Fracture healing in the elderly patient.41(11):1080-93.

7. Kline AJ, Gruen GS, Pape HC, Tarkin IS, Irrgang JJ, and Wukich DK. Early Complications Following the Operative Treatment of Pilon Fractures With and Without Diabetes. Foot \& Ankle International.30(11):1042-7.

8. Rodriguez EK, Boulton C, Weaver MJ, Herder LM, Morgan JH, Chacko AT, et al. Predictive factors of distal femoral fracture nonunion after lateral locked plating: $A$ retrospective multicenter case-control study of 283 fractures. Injury.45(3):554-9.

9. Foulk DA, and Szabo RM. Diaphyseal humerus fractures: Natural history and occurrence of nonunion. Orthopedics. 1995;18(4):333-5.

10. Castillo RC, Bosse MJ, Mackenzie EJ, and Patterson BM. Impact of Smoking on Fracture Healing and Risk of Complications. 2005;19(3):151.

11. Cobb TK, Gabrielsen TA, Campbell DC, 2nd, Wallrichs SL, and Ilstrup DM.

12. Gerber HP, Vu TH, Ryan AM, Kowalski J, and Ferrara N. VEGF couples hypertrophic cartilage remodeling, ossification, and angiogenesis during endochondral bone formation. Nature Medicine. 1999;5.

13. Zelzer, and E. VEGFA is necessary for chondrocyte survival during bone development. Development.131(9):2161-71.

14. Hu K, Olsen BR, Hu K, and Olsen BR. Osteoblast-derived VEGF regulates osteoblast differentiation and bone formation during bone repair. Journal of Clinical Investigation. 2016.

15. Maes C, Carmeliet G, and Schipani E. Hypoxia-driven pathways in bone development, regeneration and disease. Nature Reviews Rheumatology.8(6):358-66.

16. Wan C, Gilbert SR, Wang Y, Cao X, Shen X, Ramaswamy G, et al. Activation of the hypoxiainducible factor-1? pathway accelerates bone regeneration. Proc Natl Acad Sci U $S$ A.105(2):686-91.

17. Holmbeck K, Bianco P, Caterina J, Yamada S, and Birkedal-Hansen H. MT1-MMP-Deficient Mice Develop Dwarfism, Osteopenia, Arthritis, and Connective Tissue Disease due to Inadequate Collagen Turnover. Cell. 1999;99(1):81-92.

18. Vu TH, Shipley JM, Bergers G, Berger JE, Helms JA, Hanahan D, et al. MMP-9/gelatinase B is a key regulator of growth plate angiogenesis and apoptosis of hypertrophic chondrocytes. 1998;93(3):411-22.

19. Zhou Z, Apte S, Soininen R, Cao R, Baaklini G, Rauser R, et al. Impaired endochondral 
ossification and angiogenesis in mice deficient in membrane-type matrix metalloproteinase I. Proc Natl Acad Sci U S A. 2000;97(8):4052-7.

20. Montero A, Okada Y, Tomita M, Ito M, and Hurley MM. Disruption of the fibroblast growth factor-2 gene results in decreased bone mass and bone formation. Journal of Clinical Investigation. 2000;105(8):1085.

21. Schmid GJ, Kobayashi C, Sandell LJ, and Ornitz DM. Fibroblast Growth Factor Expression During Skeletal Fracture Healing in Mice. Dev Dyn. 2009;238(3):766-74.

22. Wang C, Inzana JA, Mirando AJ, Ren Y, Liu Z, Shen J, et al. NOTCH signaling in skeletal progenitors is critical for fracture repair. J Clin Invest. 2016;126(4):1471-81.

23. Ramasamy SK, Kusumbe AP, Wang L, and Adams RH. Endothelial Notch activity promotes angiogenesis and osteogenesis in bone. Nature. 2014.

24. Coste B, Mathur J, Schmidt M, Earley TJ, Ranade S, Petrus MJ, et al. Piezo1 and Piezo2 are essential components of distinct mechanically activated cation channels. Science (New York, NY). 2010;330(6000):55-60.

25. Coste B, Xiao B, Santos JS, Syeda R, Grandl J, Spencer KS, et al. Piezo proteins are pore-forming subunits of mechanically activated channels. Nature. 2012;483(7388):176-81.

26. Ge J, Li W, Zhao Q, Li N, Chen M, Zhi P, et al. Architecture of the mammalian mechanosensitive Piezo1 channel. Nature. 2015;527(7576):64-9.

27. Saotome K, Murthy SE, Kefauver JM, Whitwam T, Patapoutian A, and Ward AB. Structure of the mechanically activated ion channel Piezo1. Nature. 2018;554(7693):481-6.

28. Zhao Q, Zhou H, Chi S, Wang Y, Wang J, Geng J, et al. Structure and mechanogating mechanism of the Piezo1 channel. Nature. 2018;554(7693):487-92.

29. Faucherre A, Kissa K, Nargeot J, Mangoni ME, and Jopling C. Piezo1 plays a role in erythrocyte volume homeostasis. Haematologica. 2014;99(1):70-5.

30. Kim SE, Coste B, Chadha A, Cook B, and Patapoutian A. The role of Drosophila Piezo in mechanical nociception. Nature. 2012;483(7388):209-12.

31. Zarychanski R, Schulz VP, Houston BL, Maksimova Y, Houston DS, Smith B, et al. Mutations in the mechanotransduction protein PIEZO1 are associated with hereditary xerocytosis. Blood. 2012;120(9):1908-15.

32. Gallagher PG. Disorders of red cell volume regulation. Curr Opin Hematol. 2013;20(3):201-7.

33. Eisenhoffer GT, Loftus PD, Yoshigi M, Otsuna H, Chien C-B, Morcos PA, et al. Crowding induces live cell extrusion to maintain homeostatic cell numbers in epithelia. Nature. 2012;484(7395):546-9.

34. Li J, Hou B, Tumova S, Muraki K, Bruns A, Ludlow MJ, et al. Piezo1 integration of vascular architecture with physiological force. Nature. 2014;515(7526):279-82.

35. Ranade SS, Qiu Z, Woo SH, Hur SS, Murthy SE, Cahalan SM, et al. Piezo1, a mechanically activated ion channel, is required for vascular development in mice. Proceedings of the National Academy of Sciences of the United States of America. 2014;111(28):10347-52.

36. Fotiou E, Martin-Almedina S, Simpson MA, Lin S, Gordon K, Brice G, et al. Novel mutations in PIEZO1 cause an autosomal recessive generalized lymphatic dysplasia with non-immune hydrops fetalis. Nature communications. 2015;6:8085.

37. Lukacs V, Mathur J, Mao R, Bayrak-Toydemir P, Procter M, Cahalan SM, et al. Impaired PIEZO1 function in patients with a novel autosomal recessive congenital lymphatic dysplasia. Nature communications. 2015;6:8329. 
38. Retailleau K, Duprat F, Arhatte M, Ranade SS, Peyronnet R, Martins JR, et al. Piezo1 in Smooth Muscle Cells Is Involved in Hypertension-Dependent Arterial Remodeling. Cell reports. 2015;13(6):1161-71.

39. Rode B, Shi J, Endesh N, Drinkhill MJ, Webster PJ, Lotteau SJ, et al. Piezo1 channels sense whole body physical activity to reset cardiovascular homeostasis and enhance performance. Nature communications. 2017;8(1):350.

40. $K N, V L, D T S, L M ~ G, A K, T W$, et al. Mechanically activated ion channel PIEZO1 is required for lymphatic valve formation. Proceedings of the National Academy of Sciences of the United States of America. 2018;115(50):12817-22.

41. D C, E P, E J, B C, S L, J Y, et al. Piezo1 incorporates mechanical force signals into the genetic program that governs lymphatic valve development and maintenance. $\mathrm{JCl}$ insight. 2019;4(5): undefined.

42. $X L, L H, I N, E M, M J S, M A$, et al. Stimulation of Piezo1 by mechanical signals promotes bone anabolism. eLife. 2019;8(undefined): undefined.

43. W S, S C, Y L, S L, Y T, Y X, et al. The mechanosensitive Piezo1 channel is required for bone formation. eLife. 2019;8(undefined): undefined.

44. MG D, DR C, WG R, MM A-B, LM S, TR K, et al. Expression and distribution of PIEZO1 in the mouse urinary tract. American journal of physiology Renal physiology. 2019;317(2):F303-F21.

45. Y W, J G, RK T, B K, S B, and EJ D. Nrf2 acts cell-autonomously in endothelium to regulate tip cell formation and vascular branching. Proceedings of the National Academy of Sciences of the United States of America. 2013;110(41):E3910-8.

46. Z Z, H C, P X, CA D, JAC K, MF A, et al. $\alpha$ T-type calcium channel determines the angiogenic potential of pulmonary microvascular endothelial cells. American journal of physiology Cell physiology. 2019;316(3):C353-C64.

47. M I, T I, T N, A D, S F, and Y Y. Pannexin 3 functions as an ER Ca(2+) channel, hemichannel, and gap junction to promote osteoblast differentiation. The Journal of cell biology. 2011;193(7):1257-74.

48. F S, M H, Y M, S N, T A, and T N. Mechanotransduction via the Piezo1-Akt pathway underlies Sost suppression in osteocytes. Biochemical and biophysical research communications. 2019; undefined(undefined): undefined.

49. MS G, J C, A V, EK R, and A N. Bone fracture healing in mechanobiological modeling: A review of principles and methods. Bone reports. 2017;6(undefined):87-100.

50. Bradaschia - Correa V, Josephson AM, Mehta D, Mizrahi M, Neibart SS, Liu C, et al. The selective serotonin reuptake inhibitor fluoxetine directly inhibits osteoblast differentiation and mineralization during fracture healing in mice. Journal of Bone and Mineral Research. 2017;32(4):821-33.

51. Kusumbe AP, Ramasamy SK, Starsichova A, and Adams RH. Sample preparation for highresolution 3D confocal imaging of mouse skeletal tissue. Nature protocols. 2015;10(12):190414.

52. Greenblatt MB, Shin DY, Oh H, Lee K-Y, Zhai B, Gygi SP, et al. MEKK2 mediates an alternative $\beta$ catenin pathway that promotes bone formation. Proceedings of the National Academy of Sciences. 2016;113(9):E1226-E35. 
Figure Legends:

Fig.1 Piezo1-tdT expression and distribution in the femora of Piezo1-tdT reporter mice.

(A) Representative confocal images of the femora in Piezol-tdT mice stained with $E M C N$ (green), RFP (red) and DAPI (blue). Insets were magnified images of the areas enclosed by white dashed boxes. Scale bars, $1 \mathrm{~mm}$ (top); $100 \mu \mathrm{m}$ (middle and bottom). (B) Bone tissue lysates, prepared from Piezo1+/+ and Piezo1-tdT mice, were resolved by SDS-PAGE and western blots probed with an antibody against red fluorescent protein (which reacts with the tdTomato moiety). Detection of GAPDH was used as loading control $(\mathrm{n}=3)$.

\section{Fig. 2 Validation of Piezo1 endothelial depletion mice (Piezo1 ${ }^{4 E C}$ mice)}

Liver endothelial cells which we freshly isolated from Piezol ${ }^{\Delta E C}$ and Piezol ${ }^{f l f l}$ mice (A) Immunofluorescence of liver endothelial cells stained with anti-CD31antibody (green) and DAPI (blue). Scale bar, $20 \mu \mathrm{m}$. (B) Gel electrophoresis of PCR end-point products. Template was DNA from liver endothelial cells isolated from three Piezol ${ }^{\mathrm{AEC}}$ mice and one Piezol ${ }^{f l f l}$ mouse. Presence of the cre recombinase transgene was shown in the top row (Cdh5-cre, 191 bps); deletion of Piezol gene was shown in the middle row ( $\triangle \mathrm{EC}, 379 \mathrm{bps}$ ); presence of LoxP sequence in Piezol gene was shown in the bottom row (Piezolflox, 189 bps). (C) Quantitative RT-PCR analysis of Piezol mRNA abundance in liver endothelial cells from Piezol ${ }^{f l f l}$ and Piezol ${ }^{\triangle E C}$ mice (n=6). (D) On the left, representative traces of change $(\Delta)$ in intracellular $\mathrm{Ca}^{2+}$ in liver endothelial cells which from Piezol $1^{\triangle E C}$ and Piezol $1^{f l f l}$ mice upon application of $5 \mu \mathrm{M}$ Yoda1. On the right, mean data for the Yoda1 response at $200 \mathrm{~s}$ in Piezol ${ }^{\triangle E C}$ and Piezol flffl mice of liver endothelial cells $(n=6)$. (E).On the left, representative traces of change $(\Delta)$ in intracellular $\mathrm{Ca}^{2+}$ in Piezol ${ }^{\Delta E C}$ and Piezol ${ }^{\text {flffl }}$ mice liver endothelial cells upon application of $20 \mu \mathrm{M}$ ATP (n=6). On the right, mean data for the ATP response at $80 \mathrm{~s}$ in Piezol ${ }^{\Delta E C}$ and Piezol ${ }^{f l f l}$ mice of liver endothelial cells $(\mathrm{n}=6)$. 
(A) Representative macroscopic photograph of fractured femora showed callus has been well-formed and well remolded in Piezol ${ }^{f l f l}$ mice at 21DPF, 42DPF compared to Piezol ${ }^{\triangle E C}$ mice (black arrows denote fracture callus). Scale bars: $1 \mathrm{~cm} . \mathrm{n}=6$ mice per genotype per time point. (B, C) A real-time $\mathrm{X}$ - ray and $3 \mathrm{D} \mu \mathrm{CT}$ radiographic comparison of 2 representative femoral fractures from Piezol ${ }^{f l f l}$ and Piezol ${ }^{\triangle E C}$ mice at $0,7,14,21,28,35$ and 42 DPF suggested persistent fracture lines (yellow arrows) at $42 \mathrm{DPF}$, revealing an established fracture nonunion in Piezol ${ }^{\triangle E C}$. Scale bars: $1 \mathrm{~cm} . \mathrm{n}=$ 6 mice per genotype per time point. (D) Representative $\mu \mathrm{CT}$ axial images of fractured femurs at 21 and 42 DPF in Piezol flfll mice showed bony trabecular and foci of mineralization compared to Piezol ${ }^{\triangle E C}$ mice. Scale bars, $1 \mathrm{~mm} . \mathrm{n}=6$ for each genotype. (E) Representative coronal view from 3D $\mu \mathrm{CT}$ data at 21 and $42 \mathrm{DPF}$ in Piezol ${ }^{\text {flffl }}$ mice demonstrated that well-formed and well-remodeling bony callus while apparent radiolucent space (yellow arrows) between broken cortices in Piezol ${ }^{\triangle E C}$ mice. Scale bars: $1 \mathrm{~mm} . \mathrm{n}=6$ for each genotype. (F) BV/TV, Tb.N, and Tb.Th were significantly higher in Piezol ${ }^{f l f l}$ mice at 14 and 42 DPF while Tb.Sp was lower. $* P<0.05$ by 2 tailed, unpaired Student's test. Results are expressed as mean \pm SEM.

\section{Fig. 4 Piezo1 $^{4 E C}$ mice show less expression of $E M C N, R U N X 2$, and $O s x$ during bone}

\section{formation}

(A, B) Representative confocal images and quantification of Piezol ${ }^{f l f l}$ and Piezol ${ }^{\triangle E C}$ mice femora stained with EMCN (green) and DAPI (blue). Insets were magnified images of the fractured areas enclosed by white dashed boxes. Scale bars, $100 \mu \mathrm{m} . \mathrm{n}=$ 6 mice per genotype per time point. (C, D) Representative confocal images and quantification of Piezol ${ }^{f l f l}$ and Piezol ${ }^{\triangle E C}$ mice femora stained with RUNX2 (red) and DAPI (blue). Insets were magnified images of the fractured areas enclosed by white dashed boxes. Scale bars, $100 \mu \mathrm{m} . \mathrm{n}=6$ mice per genotype per time point. (E, F) Representative confocal images and quantification of Piezol ${ }^{f l f l}$ and Piezol ${ }^{\Delta E C}$ mice femora stained with $O s x$ (red) and DAPI (blue). Insets were magnified images of the fractured areas enclosed by white dashed boxes. Scale bars, $100 \mu \mathrm{m}$. $\mathrm{n}=6$ mice per genotype per time point. ${ }^{*} P<0.05$ by 2 -tailed, unpaired Student's test. Results are 
expressed as mean \pm SEM.

\section{Fig. 5 Loss of endothelial Piezo1 results in histological changes}

(A) Representative images of H\&E staining of femora at 21 and 42 DPF between Piezol flfl and Piezol ${ }^{\triangle E C}$ mice. $\mathrm{n}=6$ mice per genotype per time point. (B) Representative images of $\mathrm{ABH} / \mathrm{OG}$ staining of femora at 21 and 42 DPF between Piezol ${ }^{f l f l}$ and Piezol ${ }^{\triangle E C}$ mice. $\mathrm{n}=6$ mice per genotype per time point. (C) Representative images of SFO/FG staining of femora at 21 and 42 DPF between Piezol ${ }^{f l f l}$ and Piezol ${ }^{\triangle E C}$ mice. $\mathrm{n}=6$ mice per genotype per time point.

\section{Fig. 6 Loss of endothelial Piezo1 severely impairs angiogenesis}

Representative $\mu \mathrm{CT}$ based angiographic images (A) and quantification of vessel volume, vessel volume fraction and vessel surface area (B). Scale bar, $1 \mathrm{~mm} . \mathrm{n}=6$ per group per time point. ${ }^{*} P<0.05$ by 2 -tailed, unpaired Student's test. Results are expressed as mean $\pm \mathrm{SEM}$.

\section{Fig. 7 Loss of endothelial Piezo1 remarkably reduces biomechanical properties}

Yield load and bending stiffness were significantly decreased in samples of $21 \mathrm{DPF}$ and 42 DPF in Piezol ${ }^{\triangle E C}$ mice compared to Piezol ${ }^{\text {flfl }}$ mice. $\mathrm{n}=6$ mice per genotype per time point. $* P<0.05$ by 2 -tailed, unpaired Student's test. Results are expressed as mean \pm SEM.

Fig. 8 Loss of endothelial Piezo1 reduces calpain activity and impairs Notch signaling pathway

(A) Calpain activity measurements of tissues from bone fracture lesions at day 21 and 42, respectively in Piezol ${ }^{\triangle E C}$ mice compared to Piezol ${ }^{f l f l}$ mice. $\mathrm{n}=6$ mice per genotype per time point. (B-F) Protein levels, determined by western blotting, and mean data for p-PI3K, p-AKT, CD31 and NIICD in Piezol ${ }^{\Delta E C}$ mice compared to Piezol flffl mice. $\mathrm{n}=$ 3 each. (G-H) mRNA levels of Hesl and Heyl were detected by real-time PCR in Piezol ${ }^{\Delta E C}$ mice compared to Piezol ${ }^{f l f l}$ mice. $\mathrm{n}=6$ each. 


\section{Figure 1}

DAPI / Endomucin / RFP / Merge

A
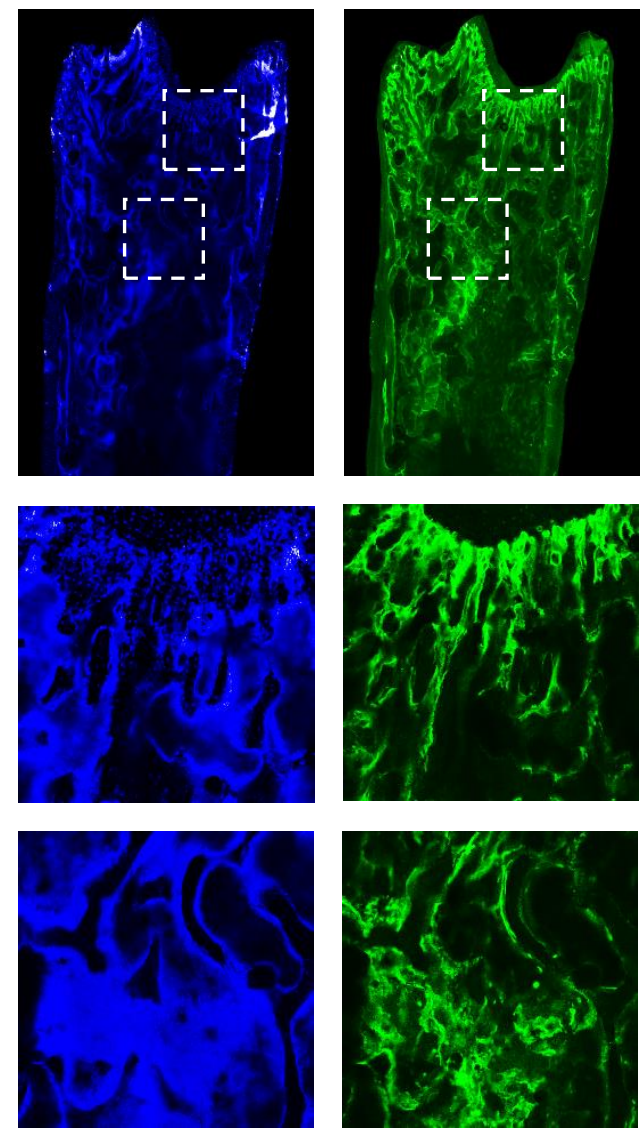

B
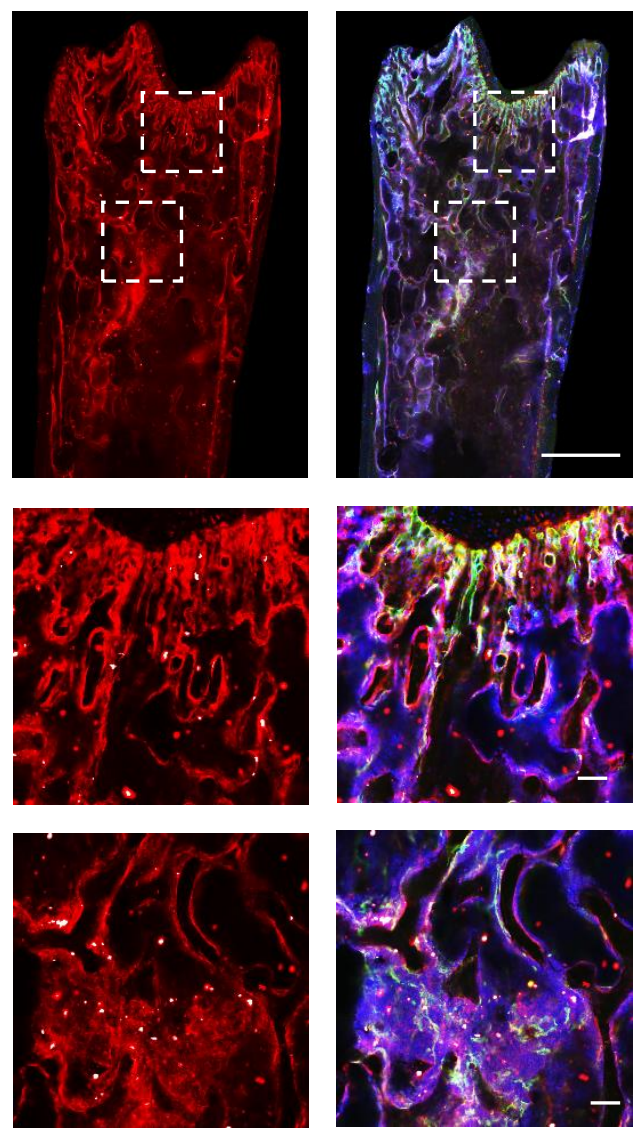

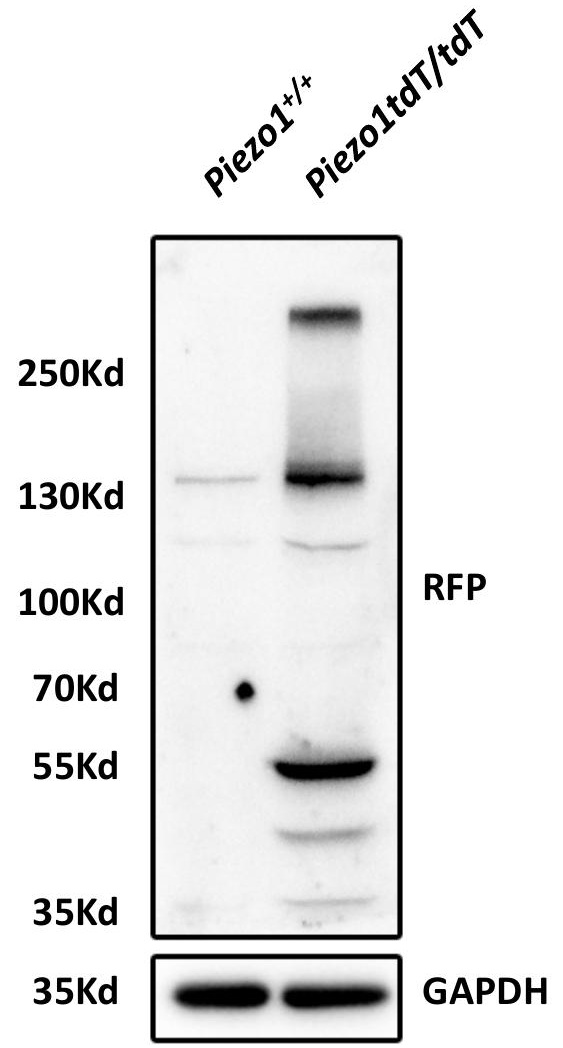


A
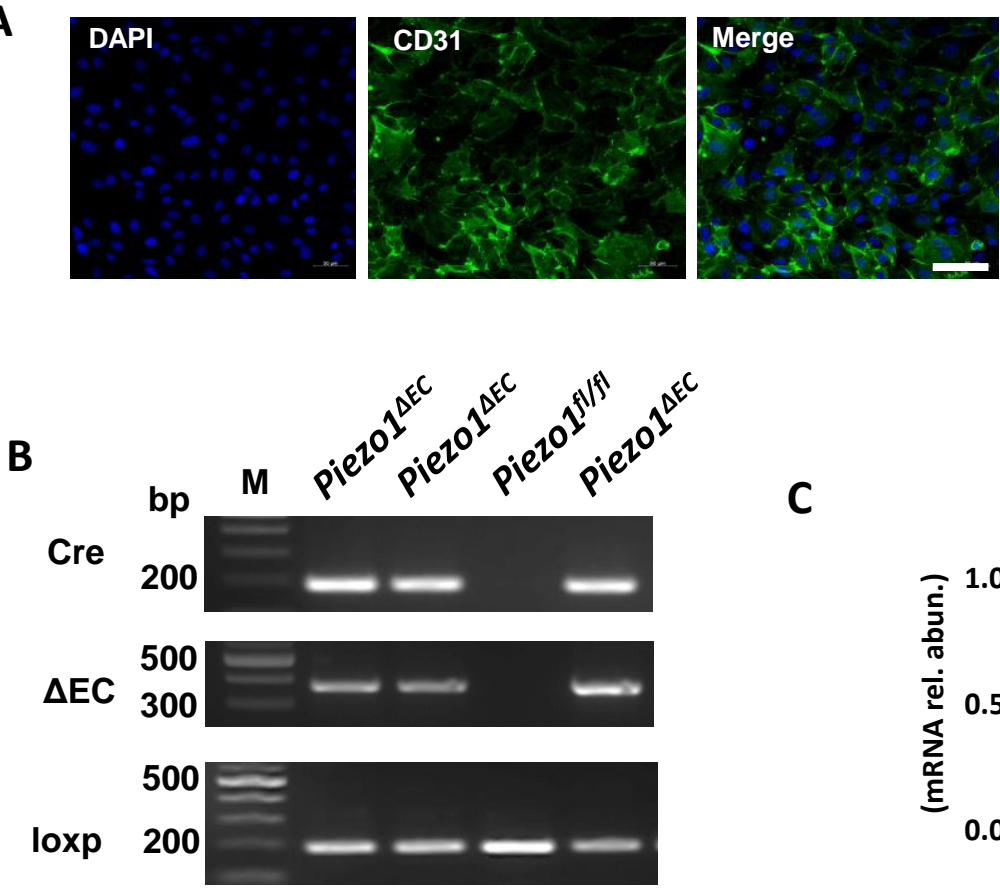

C

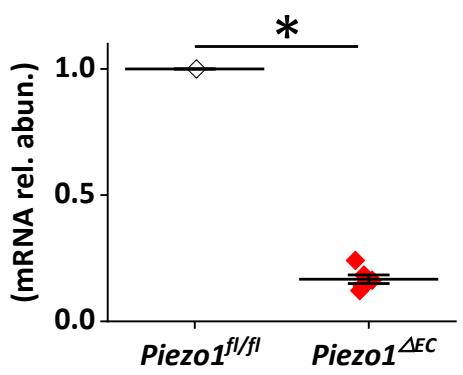

D
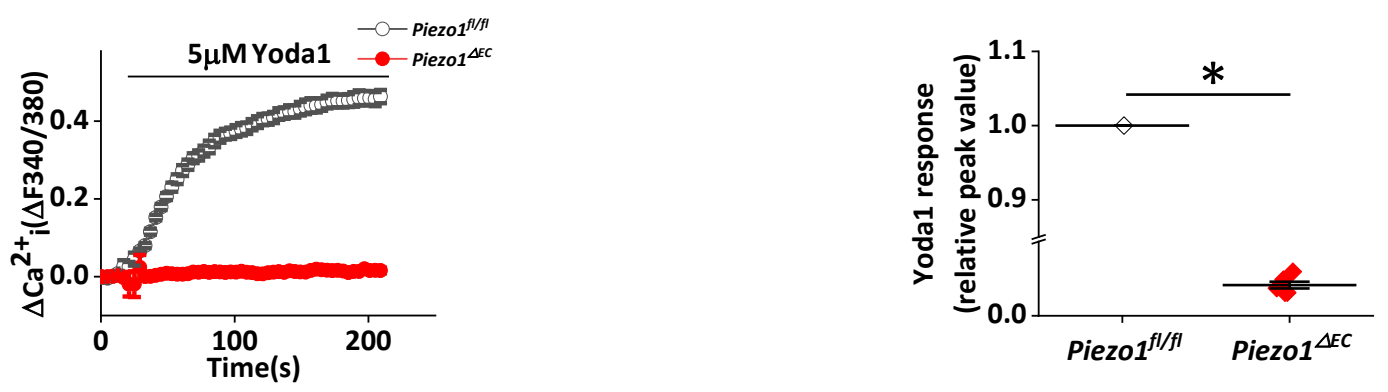

E
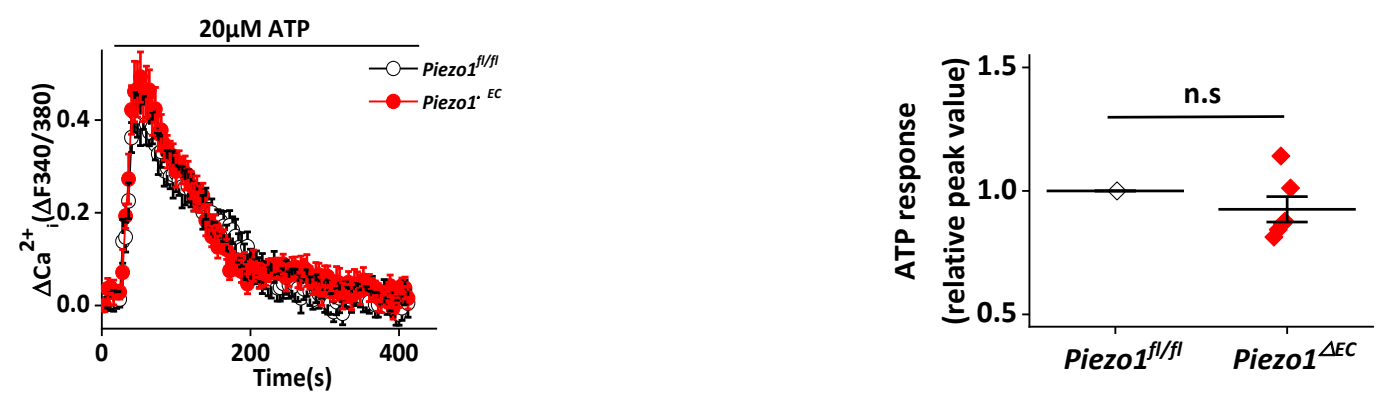


\section{Figure 3}
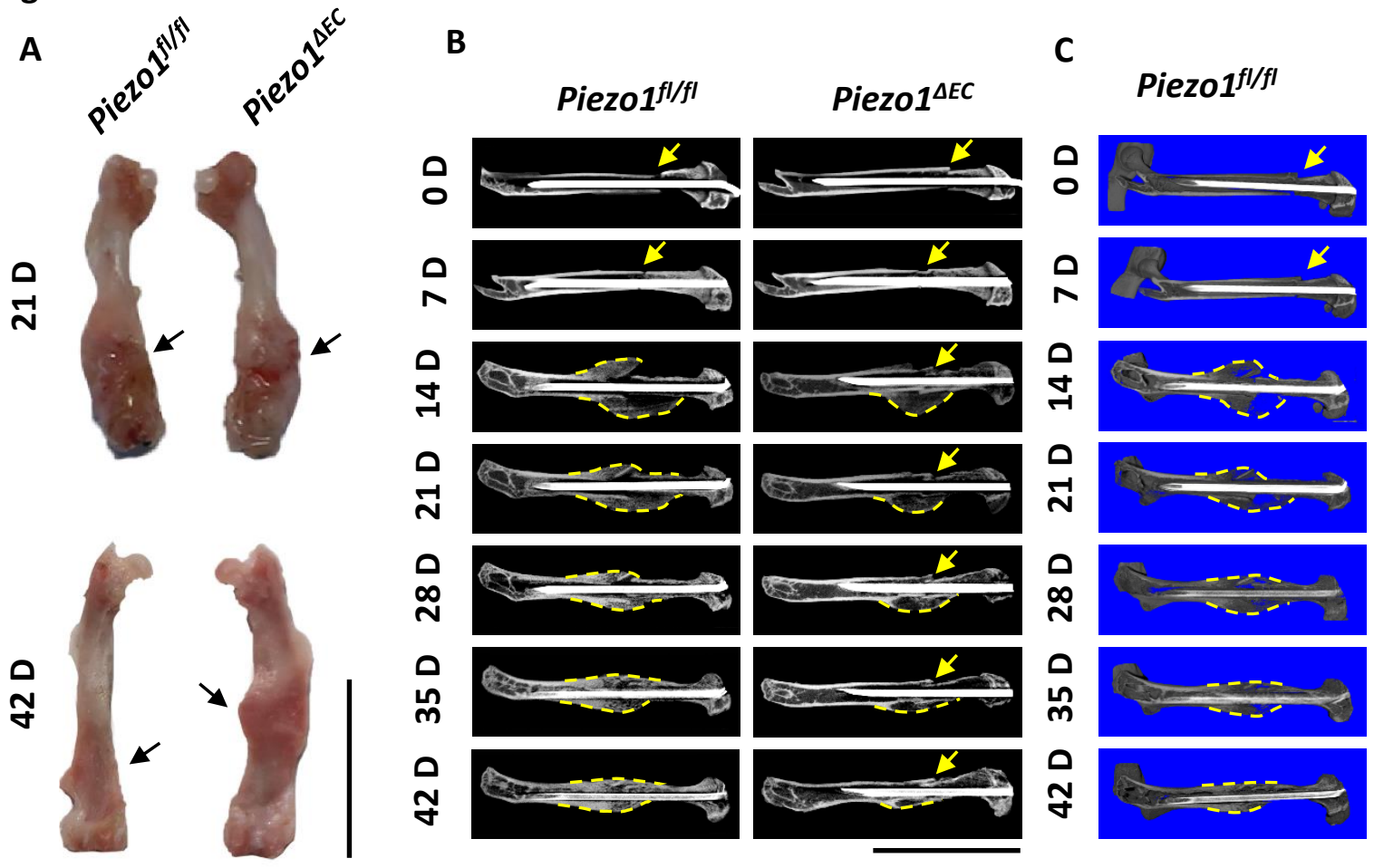

\section{Piezo1 $^{\Delta E C}$}

D

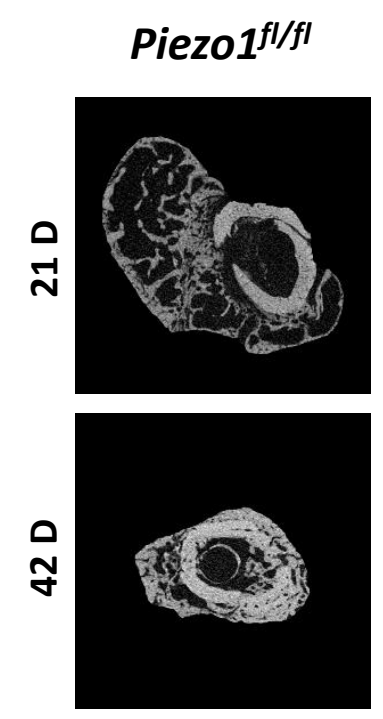

Piezo1 $^{\triangle E C}$
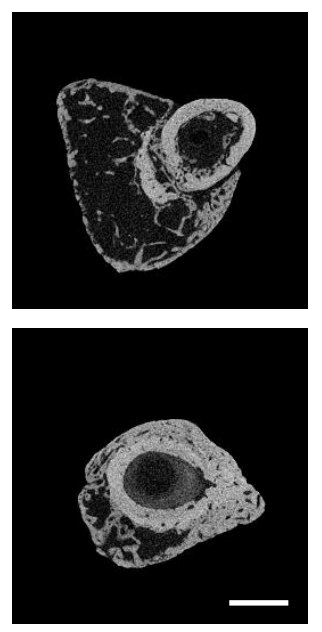

E
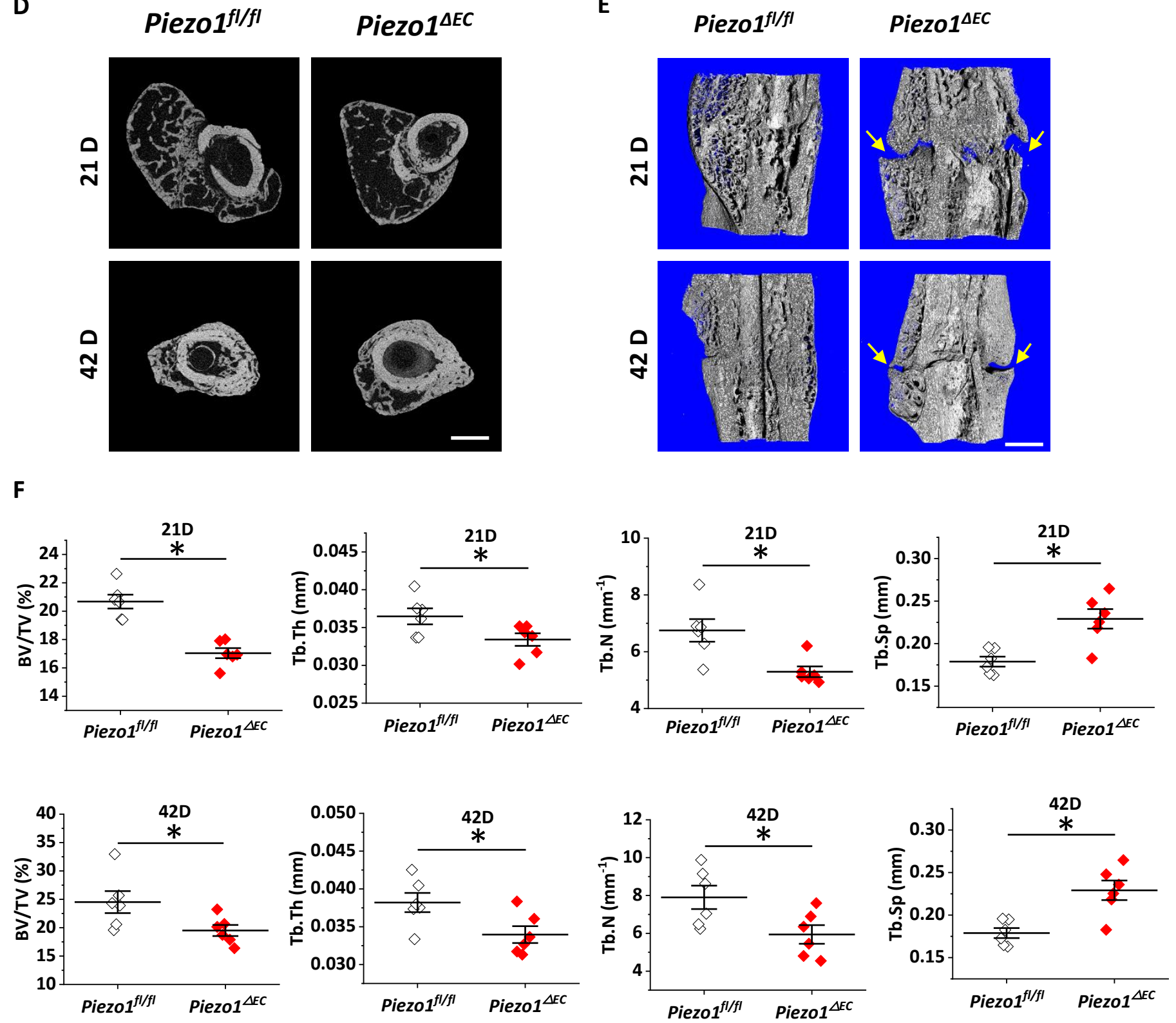

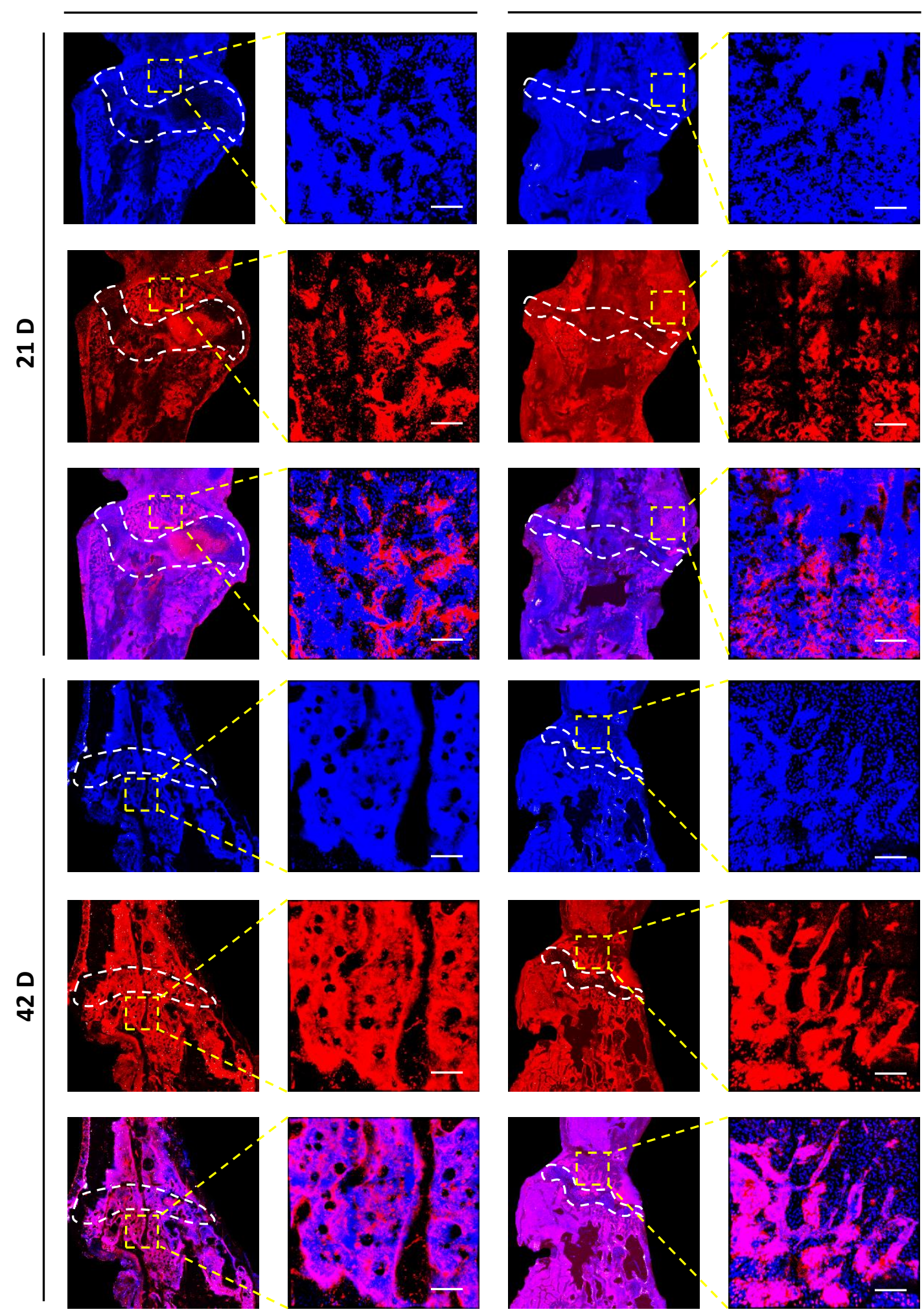

D
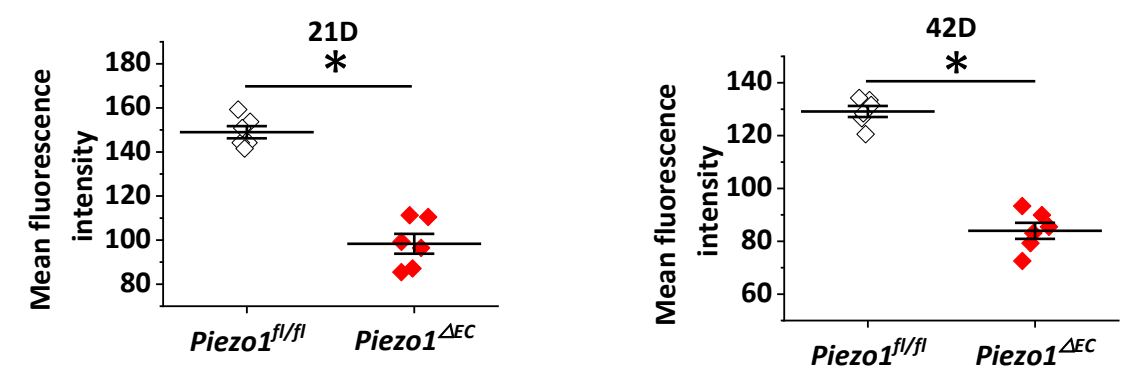
Piezo1 ${ }^{f / f l}$
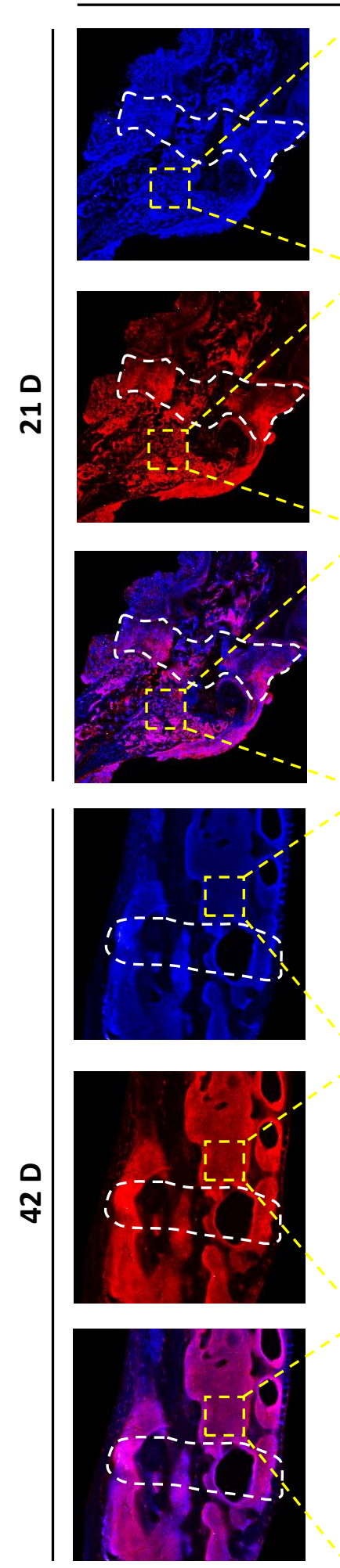
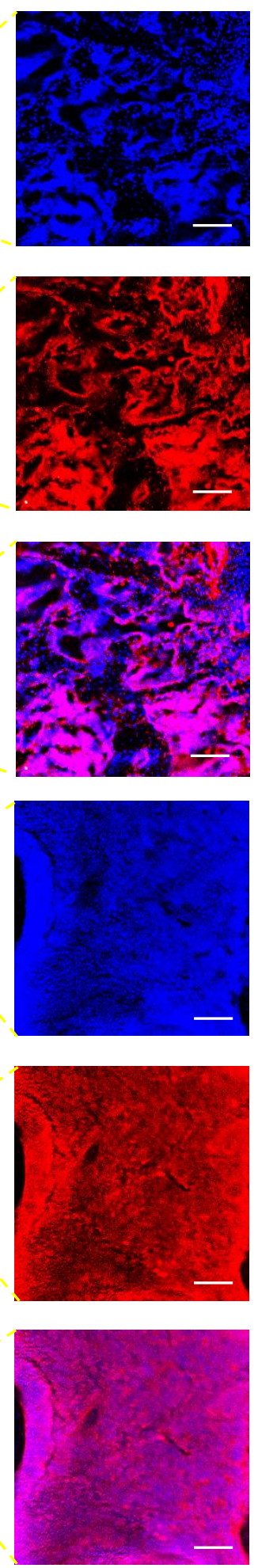

\section{Piezo1 $^{\triangle E C}$}
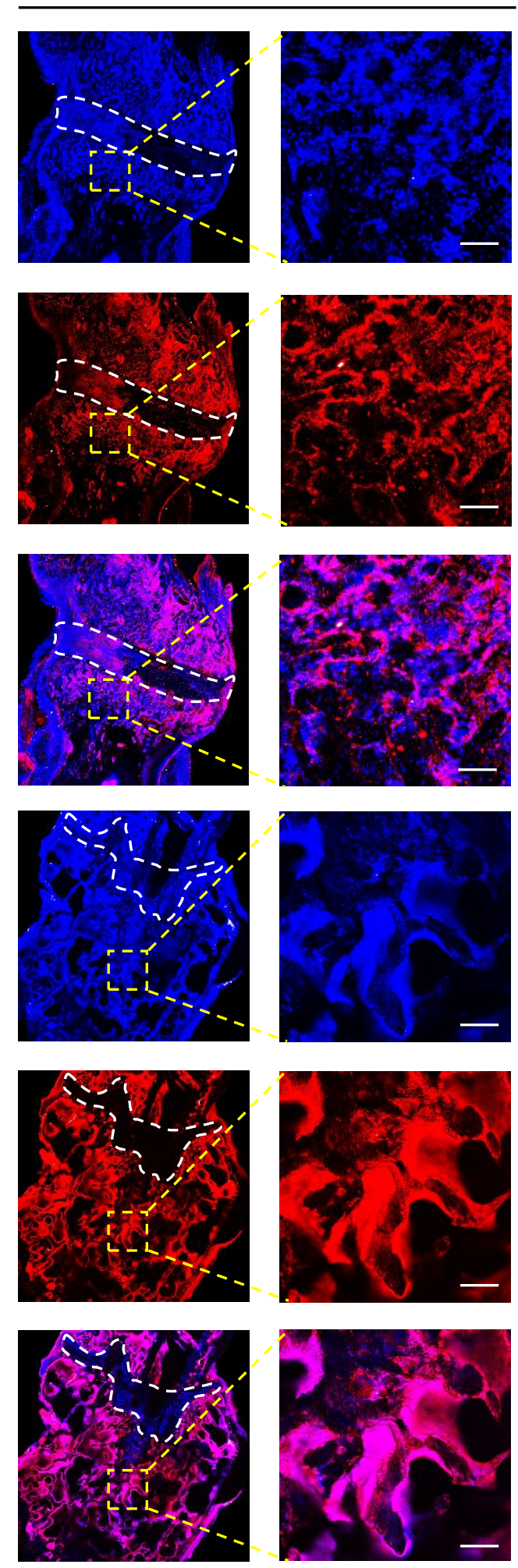

F
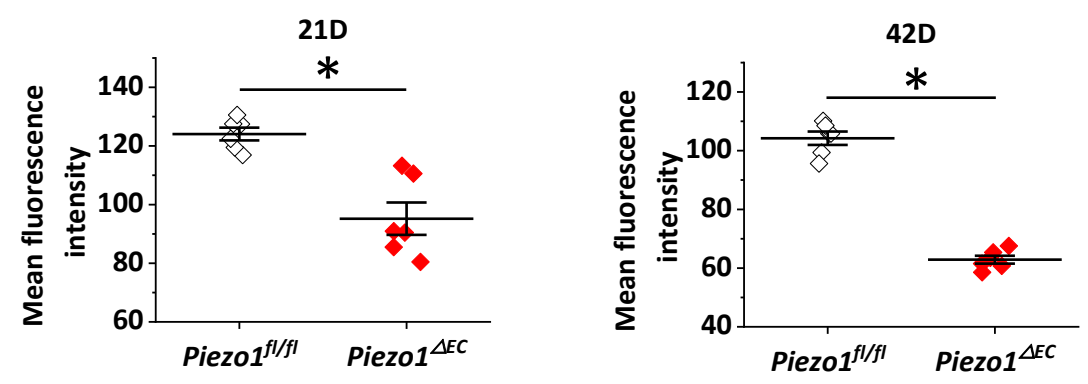
Figure 5

A

Piezo1 $1^{f l / f l}$

Piezo1 $^{\triangle E C}$
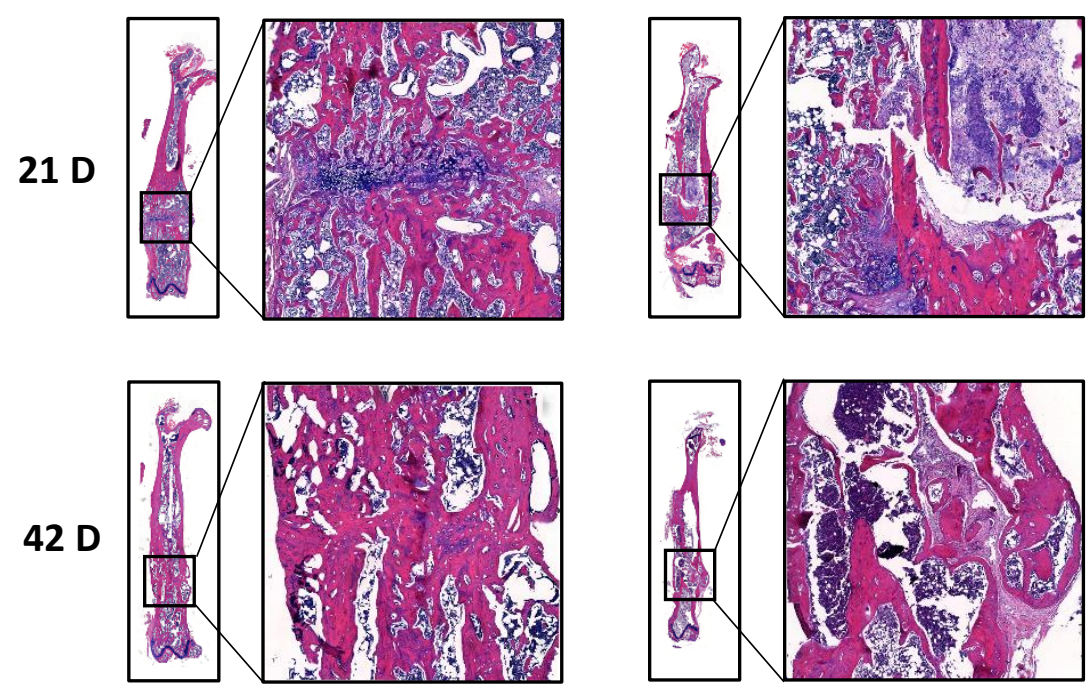

B

Piezo1 ${ }^{f / f l}$

Piezo1 $^{\triangle E C}$
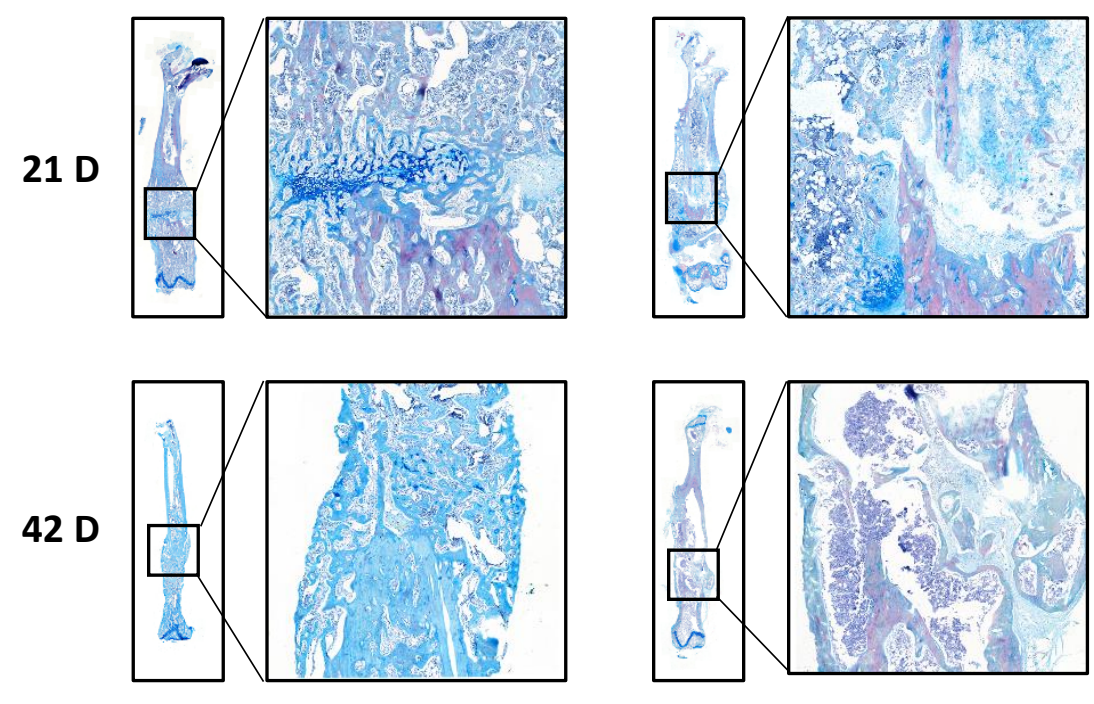

C

Piezo1 ${ }^{f l / f l}$

Piezo1 $^{\triangle E C}$
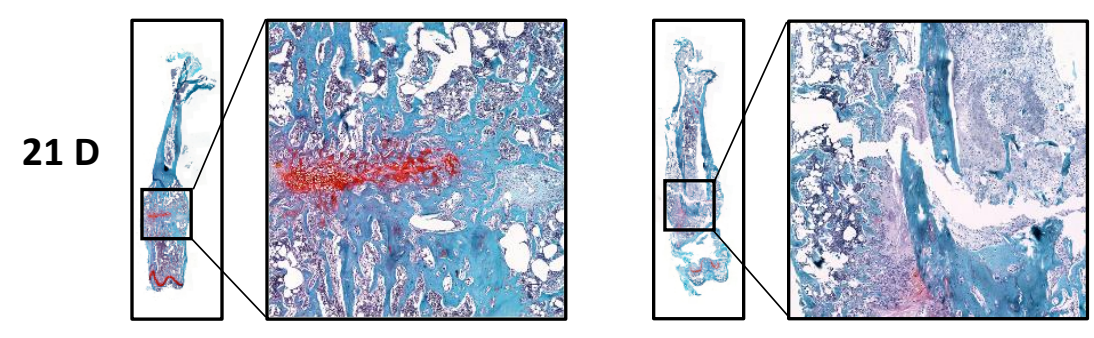

42 D
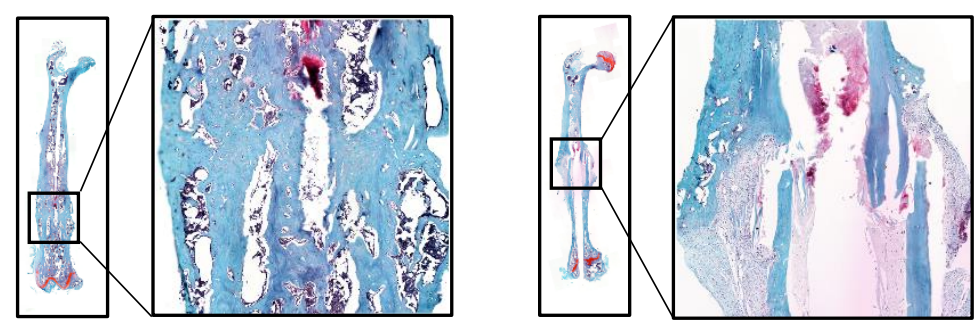
Figure 6

A Piezo1 ${ }^{f / f l}$

Piezo1 $^{\triangle E C}$
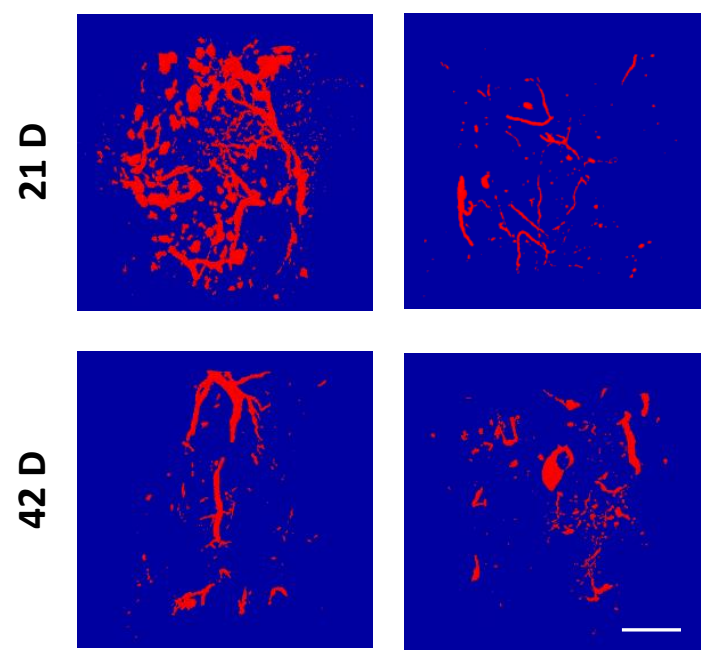

B
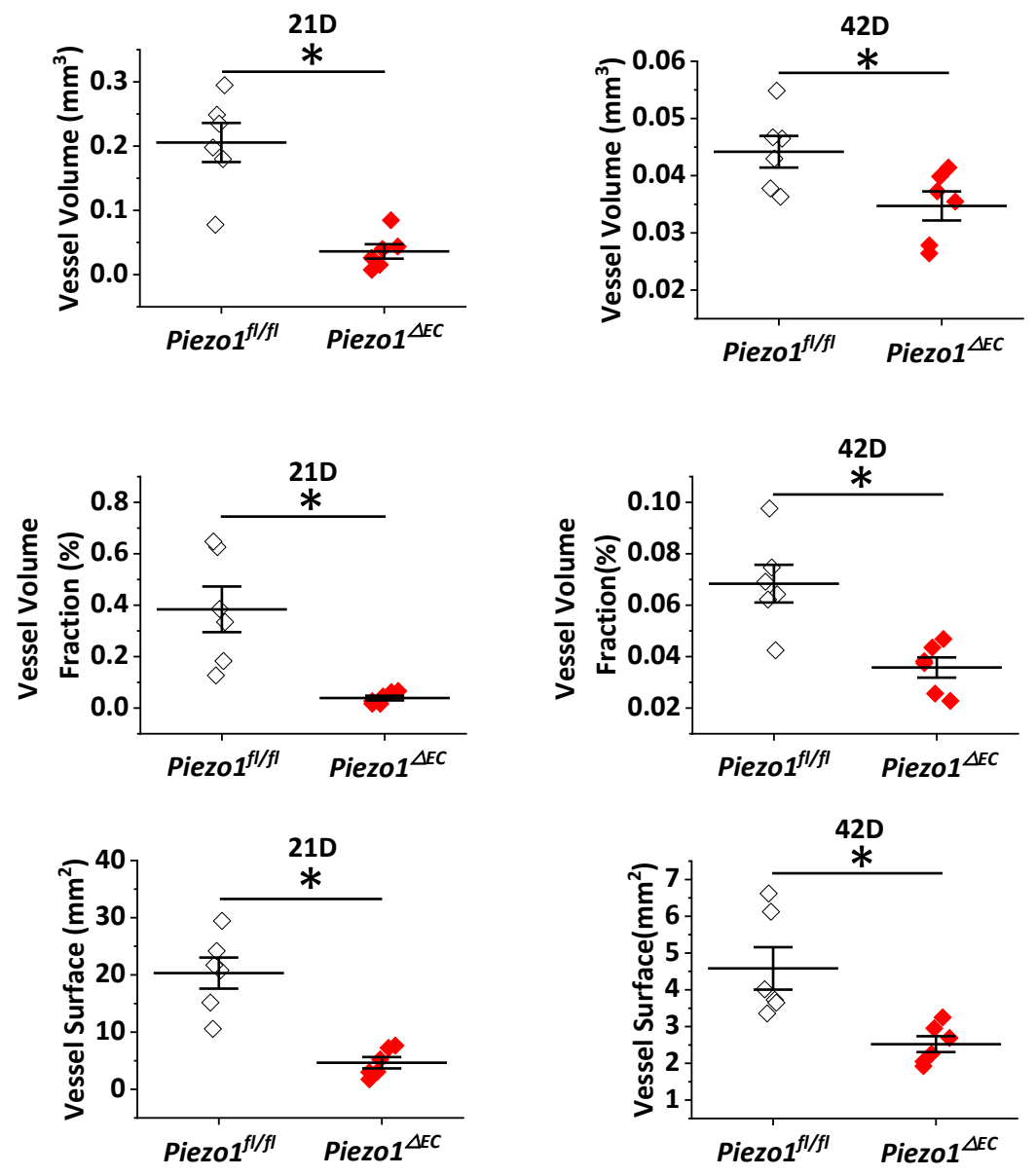
Figure 7
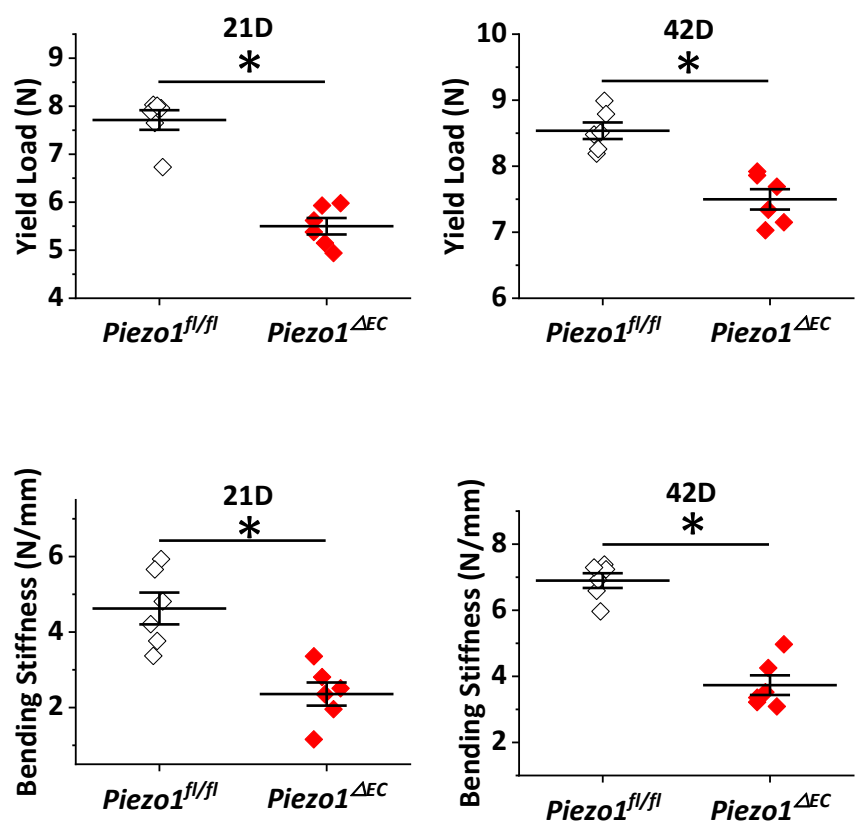
Figure 8

A

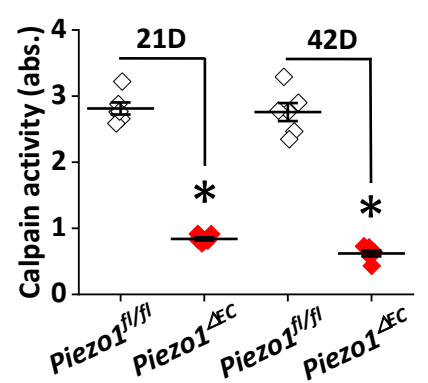

B
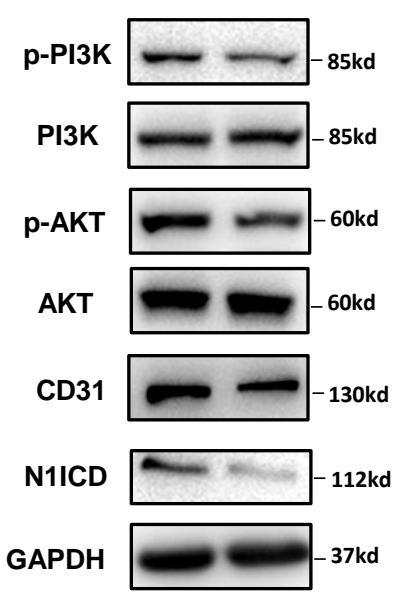

D

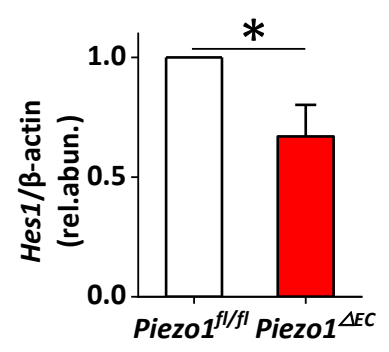

C
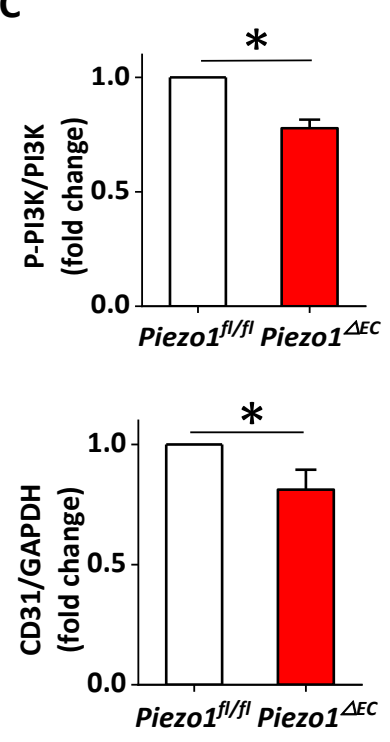
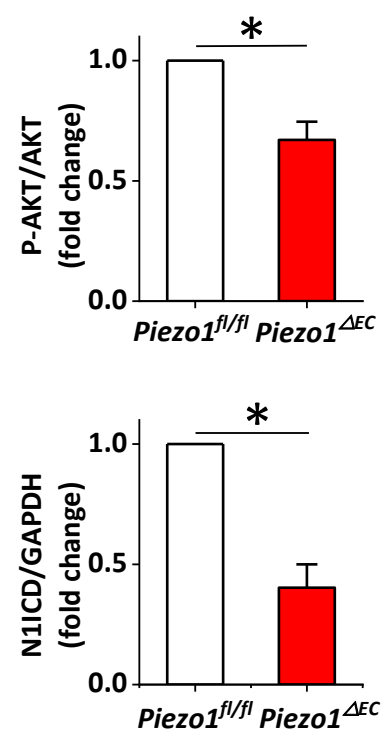

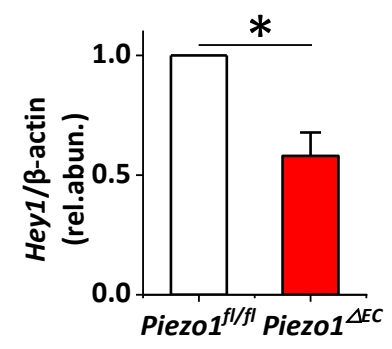

